$$
\begin{aligned}
& \text { النمذجة السببية للعلاقات بين النظريات الضمنية في الانفعال والتنظيم الانفعالي (وفق التقاديم }
\end{aligned}
$$

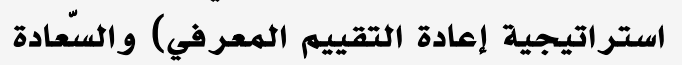

$$
\begin{aligned}
& \text { و عبد السلام هاني عبد الرحمن* }
\end{aligned}
$$

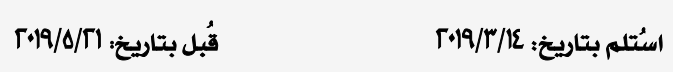

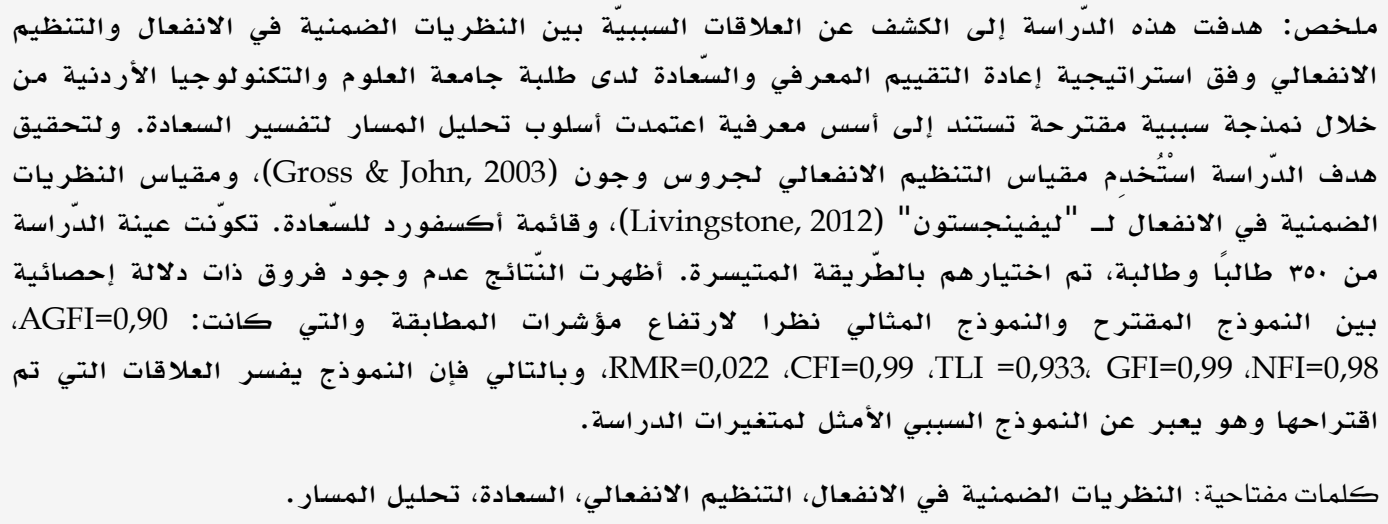

\title{
Causal Relationship Modeling of the Implicit Theories of Emotion and Emotion Regulation in View of the Cognitive Reappraisal Strategy and Happiness
}

Abdelsalam H. Abdelrahman* \& Khaldoun I. Al Dbabi UNRWA, Jordan Emam Abdelrahman Bin Faisal University, Saudi Arabi

Abstract: The purpose of this study was to unveil the causal relationship modeling of the implicit theories of emotion and emotion regulation in view of cognitive reappraisal strategy and happiness for the students of the Jordanian University of Science and Technology (JUST). Based on scientific foundations, the study has constructed a proposed causal relationship model using path analysis for interpreting happiness. To achieve this goal, the emotion regulation, by Gross and John (2003), the implicit theories of emotion Scale of Livingstone, (2012), and the Oxford Happiness Inventory were employed. The sample consisted of 350 students who were chosen on availability grounds. The results of the study showed no statistically significant differences between the proposed and the optimal causal relationship models due to high matches on: AGFI=0.90, NFI=0.98, GFI=0.99, TLI =0.933, CFI=0.99, RMR=0.022. Thus, the model explained the relationships proposed and represented the optimal causal relationship model for the variables of the study.

Keywords: : Implicit theories of emotion, emotion regulation, happiness, path analysis.

$\star$ aaa Salamhani@yahoo.com 
الهترتبة عن إسهامات استراتيجيات التنظيه

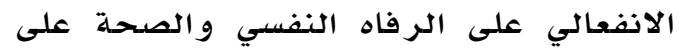
حد السو اء (Castella et al., 2013). فالسعادة (Happiness) من التوابع الههمهة

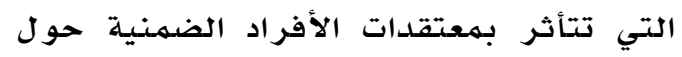
انفعالاتهم، و التي لها دور أساسي في نجاح نهاح الفرد و تحقيقه التكيف الوظيفي مـع الأحداث

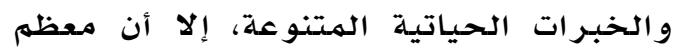

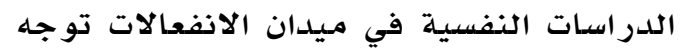

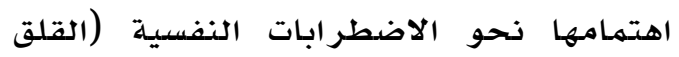

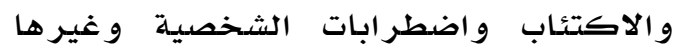

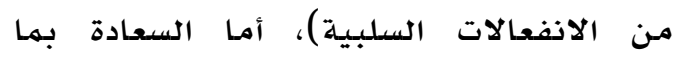

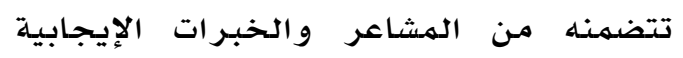

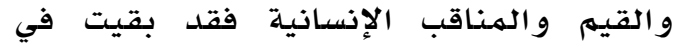

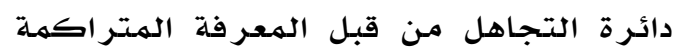

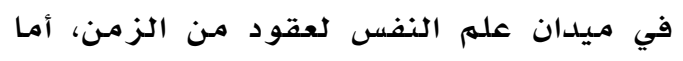

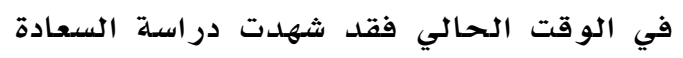

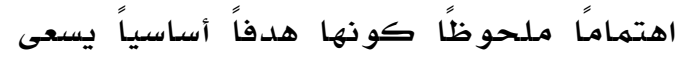

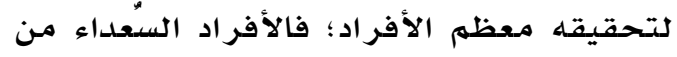

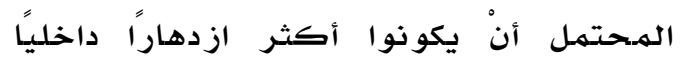

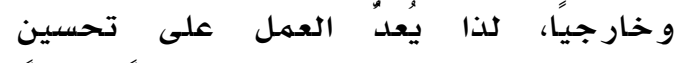

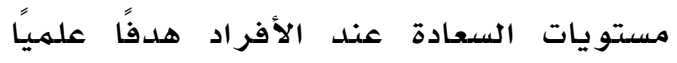

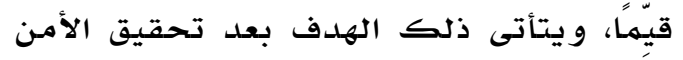

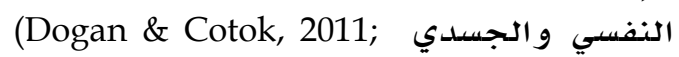
.Khan, 2009 ; Nistor, 2011)

و يعد تقديم تعريف واحد لمفهوم السعادة

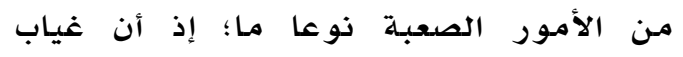
الأساس النظري للسعادة وتعدد الهعاني بتعددد

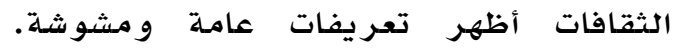

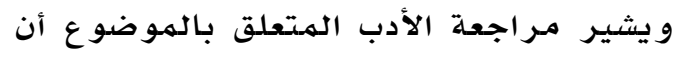
هناك محاو لات عديدة لوضع تعريف لها منذ

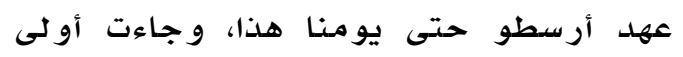

المـحاو لات البحثية لتعريف السعادة عام 1969 السعادة النفسية إذ جاء عملهه هذا كانتقال

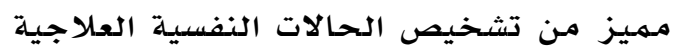

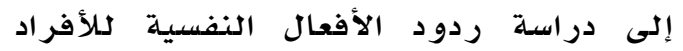

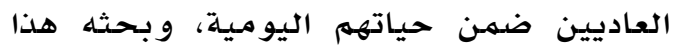
نجم عنه اهتمامات في الكيفية التي يتعامل الأفراد بها مـع صعوبات الحياة اليومية التي
غدت السعادة واحدة مـن المفاهيم الأكثر أهمية في مجال علهم النفس الإيجابي، لما لها

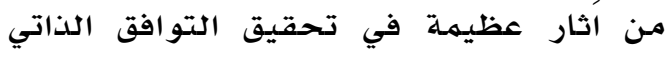

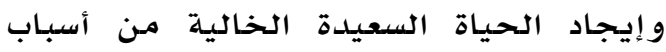

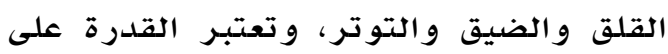

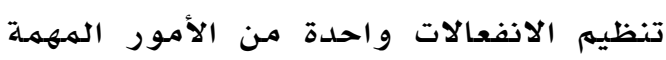

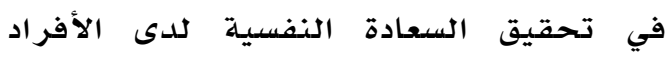

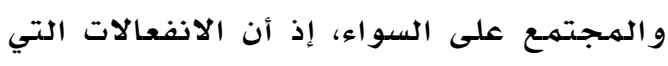
نشعر بها ونعبر عنها مهمهة جدا لسلامتنا

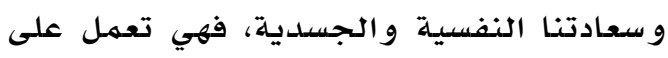

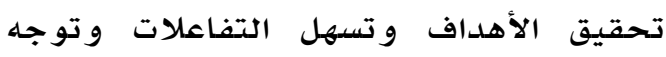

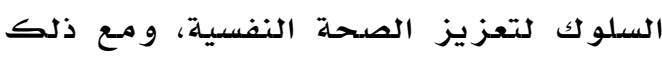

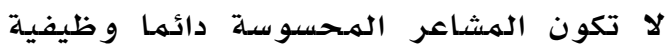
و تكيفية، فمثثلا قد تجعل الانفعالات الأفراد يختارون مسار عمل غير مناسب أو يعطلون

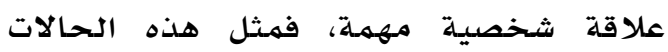
يكون من الضروري تنظيم الفرد لانفعالاته من أجل تقديم الاستجابة المناسبـة و الملائمهة

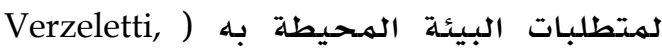
.(Zammuner, Galli \& Agnoli, 2016 ويلاحظ من الدرراسات المبكرة أن الأفراد يختلفون بمعتقداتهم حول طبيعة انفعالاتهم؟؛

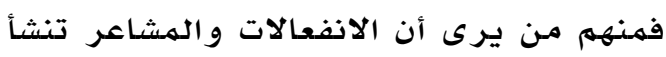

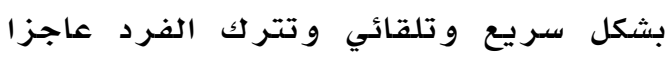
وسلبيا، ومنهم من ير اها عمليات ديناميكية تخدم الوظائف الأساسية في الحياة اليومئية

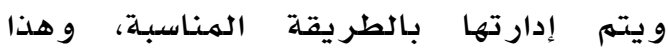

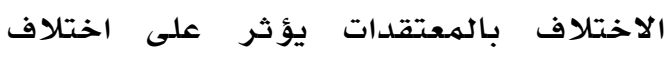

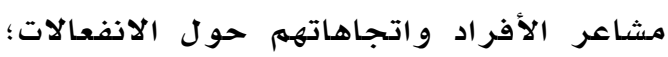

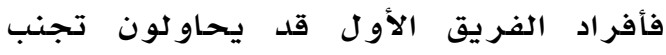

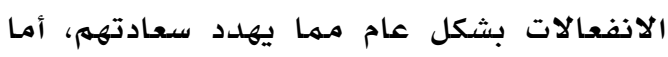
أفراد الفريق الثاني فإنهم أكثر قدرة على

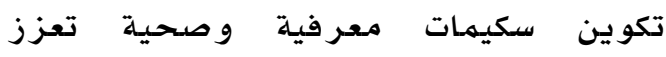

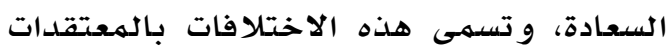
الضمنية في الانفعال التي لا تؤثر في سعادة

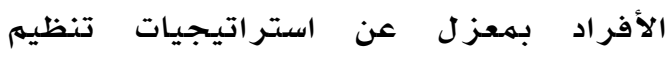

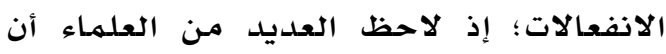

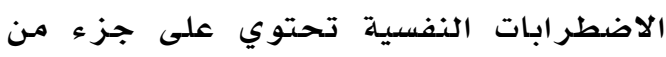

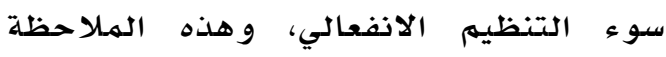
أثارت اهتمام الكثير من الباحثين حول الآثار 
الأولى لها ستة أبعاد (الاستقلال و النمو

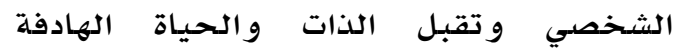

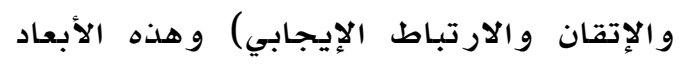

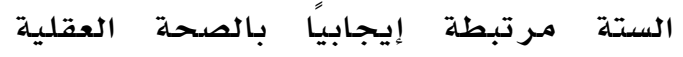

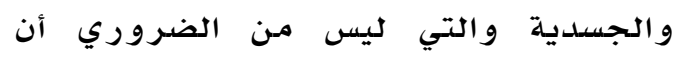

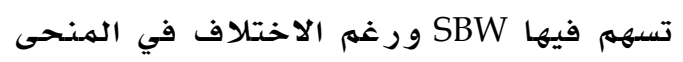

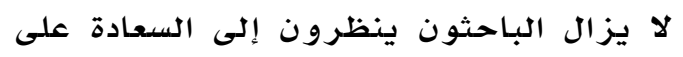

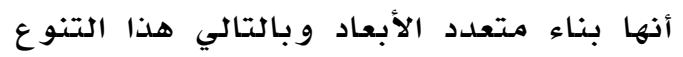
في الأبعاد يسبب غموضاء وتناقضا في الأسس ونس

البحثية (Padhy, Chelli \& Padiri, 2015).

وقد شهدت السنوات الماضية تقدما كبيرا مدهلا في الأبحاث التجريبية عن التهنية السعادة،

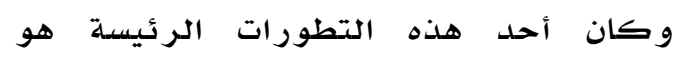

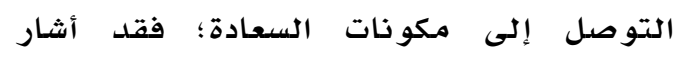

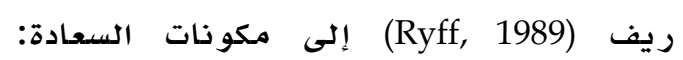

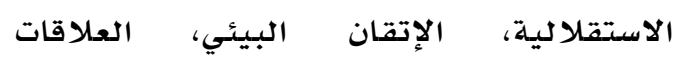

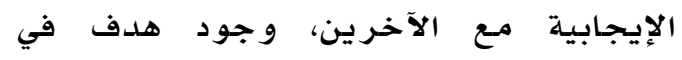

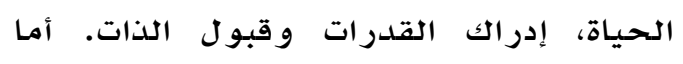

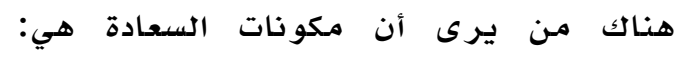

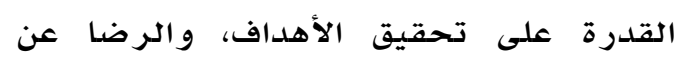

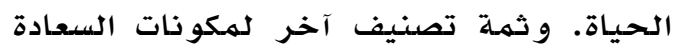

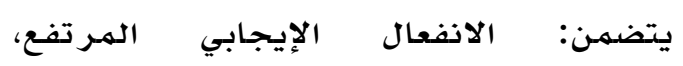

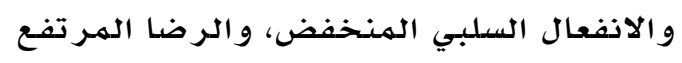
عن الحياة. ومـع التركيز على هذا المفهوم

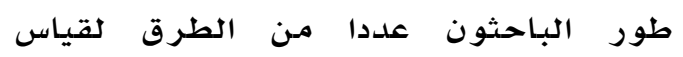

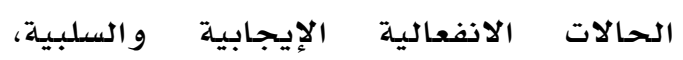
بالإضافة إلى الرضا العام عن الحياة، والتي

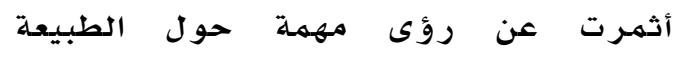

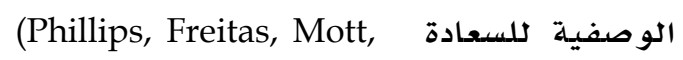
.(Gruber \& Knobe, 2017 ويرى ريتشارد (Richard, 2006) أن" هناك

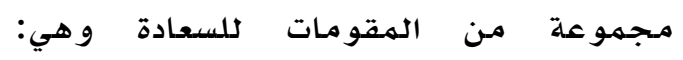
الاستقرار: و وتعني التمسك من بأحكام السعادة

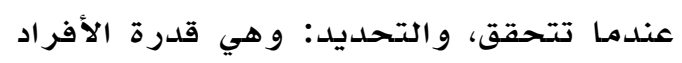

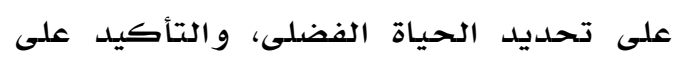
الوقت: و تعني تقييم للحياة، لذا يمكن الحكمم

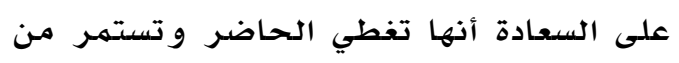

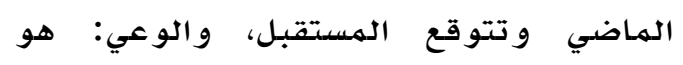

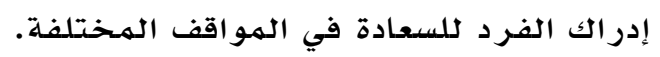

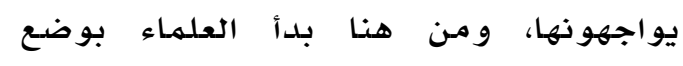

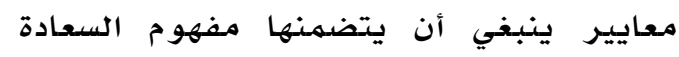
وهي: الفاعلية الإيجابية، الرضا عن الريدية الدياة،

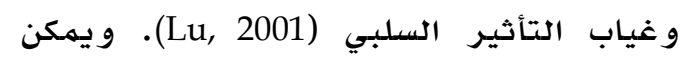
تعريف السعادة حسب منظمهة الصحة العالمية

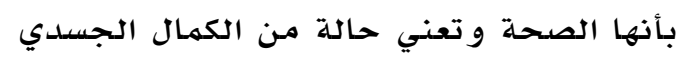

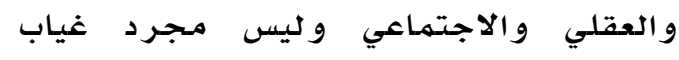

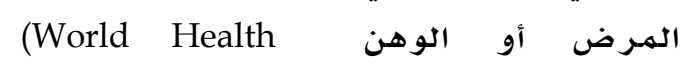

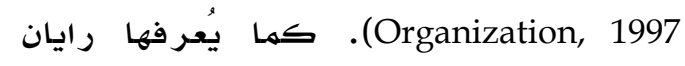
و ديسي (Ryan \& Deci, 2001) بأنها مـجمهو عة فئ شروط و وظروف من تجارب وخبرات التكامل. أما سليجرمان (Seligman, 2004) يعرفها: بأنها حالة ذهنية أو شعور يتضمن امنان

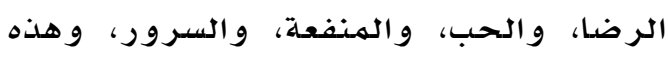

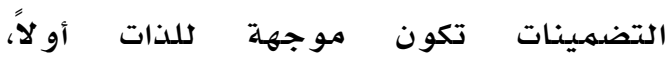

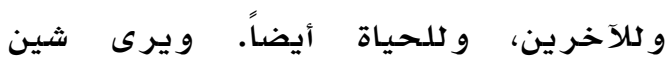
وجونسون (Shin \& Johnson 1978) وللذينان قدما تعريفا أكثر قربا للسونادة: على أنها

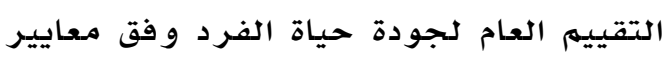

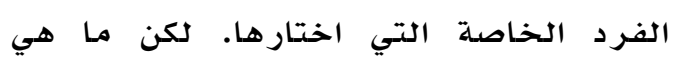

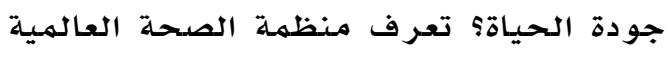

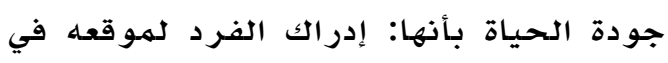
سياق الثقافة ونظام القيهم الذي يعيث فيهاه

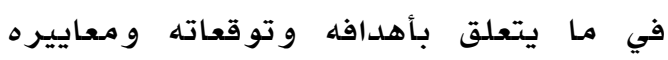

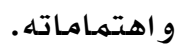

إن الدارس للخلفية التاريخية للسعادة يرى النى أنه يجب النظر إليها من منظورين أساسيين

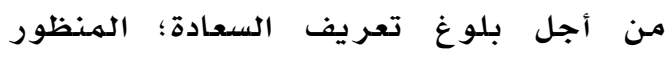
الأول هو السعادة الذاتية أو اللذة (Subjective Well-Being) (Hedonic يركز على السعادة و المشاعر الإيجابية

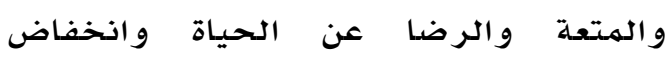

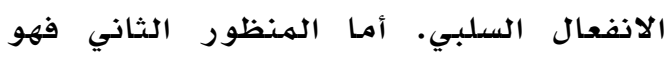

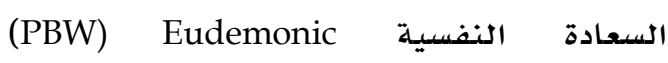
(Psychological Well Being)

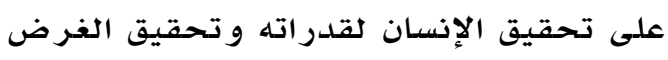
من الحياة و النـمو الإنساني، كما أن النسان السعادة

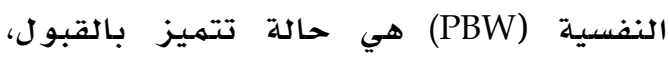
و التحقيق و التهاسك والنتكامل مـع الآخرين، وإن مفهوم (PBW) يختلف عن (SWB) بأن 
الضمنية في الانفعالات Implicit Theories of Emotion)

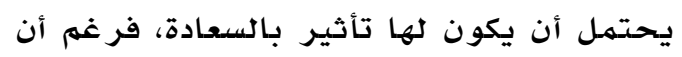

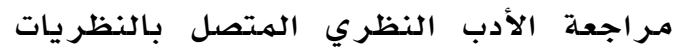
الضمنية تشير إلى أن معظم الأعمال التي الادئ

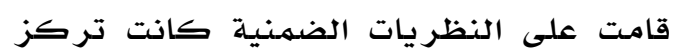

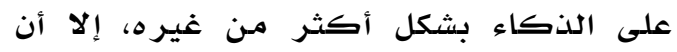

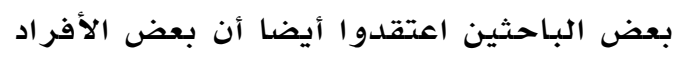

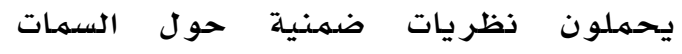

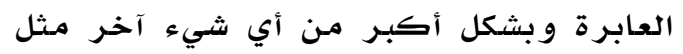

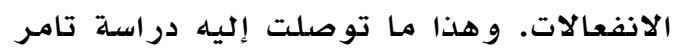
وجون وسريفاتافا وجروس مالانس ( Tamir, John,

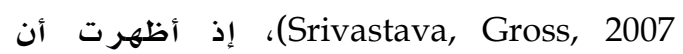

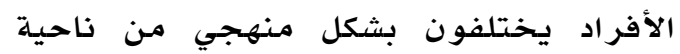

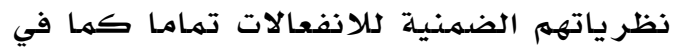
الذكاء، وتعتبر دويك Dweck وزملاؤها

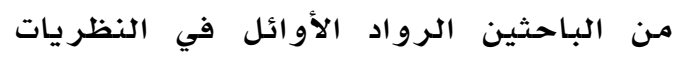

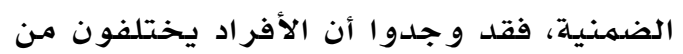

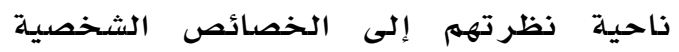

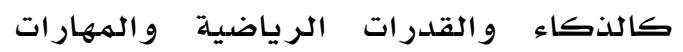

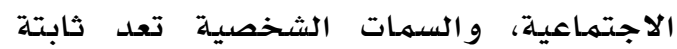

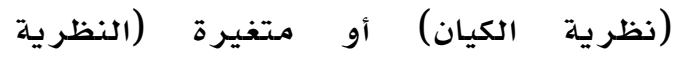

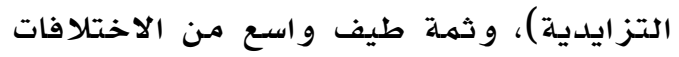
بين هاتين النظريتين، وهذه الاختلافات

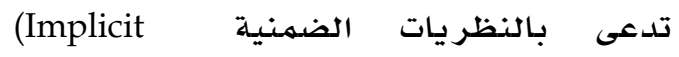
Theories كامنـة وضمنية أكثر من كونها و اضححة. إذ يختلف الأفر اد في معتقداتهم الضمنية

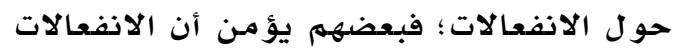
ثابتة وهم من يطلق عليهم أتباع نظرية الكيان (Entity Theory)، و يمتاز هؤلاء بأنهم

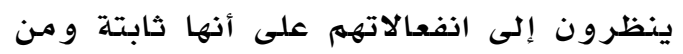

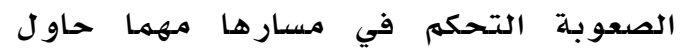

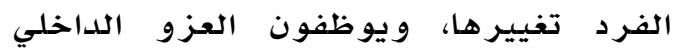
الهستقر مـع الفشل في توظيف استر اتيجيـات

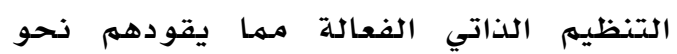

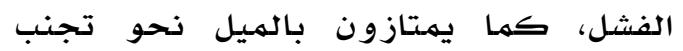

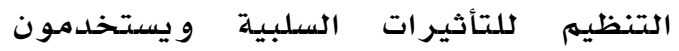

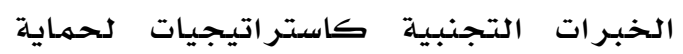
الذات؛ إذ أنهم ينظرون إلى التأثيرات غير
و تتأثر السعادة بمهمهوعة مـن العوامل أهمها:

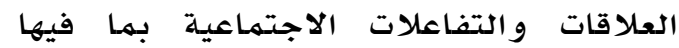

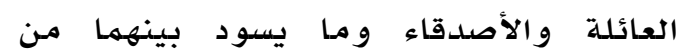

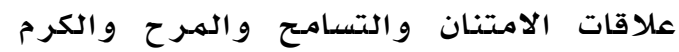

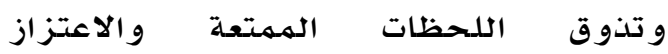
بالإنجازات لهما لها من تأثير إيجابي على الهابـ

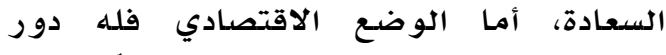

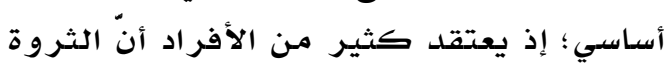

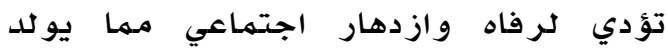

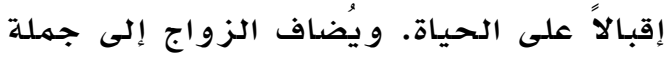

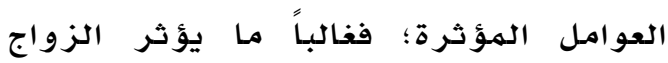
إيجابيًا في تحقيق السعادة بين الأفراد، أما فئ

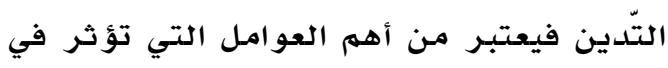

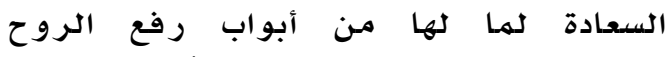

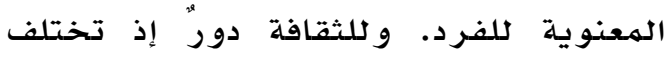

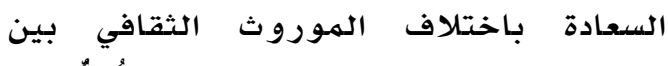

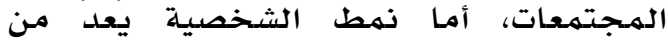

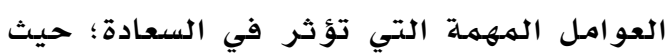
إن الشخصية الانبساطية تمتاز بسعادة بشكل إنهل أكبر من الشخصية الانطوائية ( Diener \&

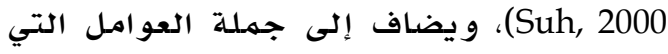
يمكن أن يكون لها دور في سعادة الأفراد:

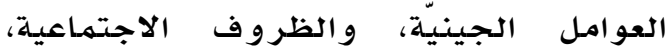

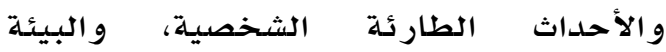

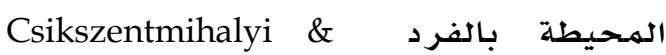

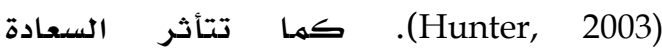

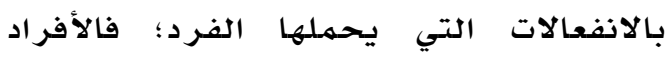

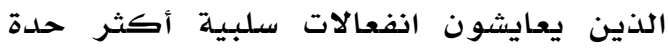
لديهم ميل أكبر لأن يمتلكوا أعراض

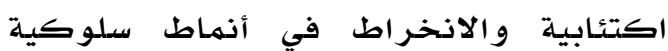
مضادة للمجتمهـع (Flynn, 2016). بناء على ما سبق تُعد السّعادة حالة ورليس

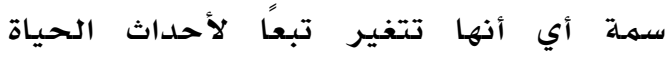

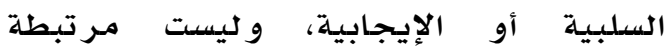

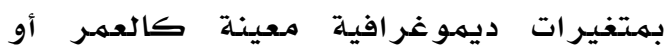
الذكاء (Langevin, 2013).

فحاول المنظرون في ميدان علهم النفس الإيجابي البحث عن تلك العوامل المول المسببية للسعادة أو تلك الإبي التي يكون لها دون دور في تحقيقها، فتم البحث في موضوع النظريات 
بالانفعالات، وومن النتائج التي تركز عليها

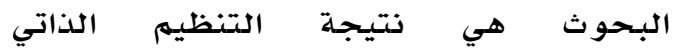
للانفعالات. حيث تهيء اعتقادات الأفر اد حول

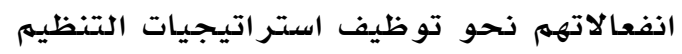
والتي تعد من التوابع الههمهة في الصححة النفسية، إذ تعد القدرة على تنظيم الانفعالات

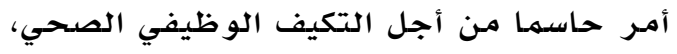
ويلاحظ أن العديد من الاضطر ابات النفسية

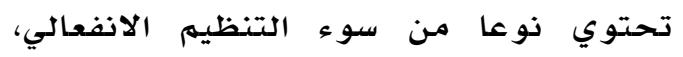

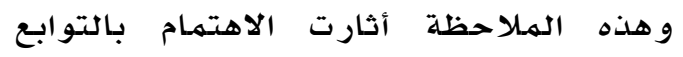

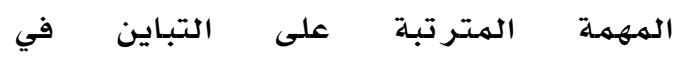

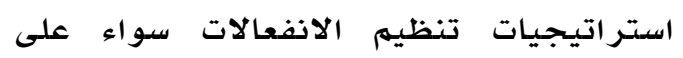

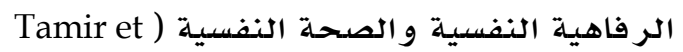
.(al., 2007

فأثارت هذه القضية اهتمام الباحثين موجهين

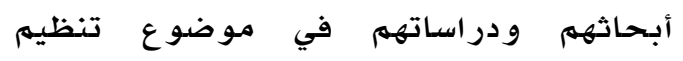
الانفعالات (Emotion Regulation) و وتأثره الهحتمل بالمعتقدات الضمنية الهية في الانفعال، و في الوقت نفسـه آثاره و نتائجه على السعادة التهاديه والصحة النفسية، إذ تعد القدرة على تنظيه

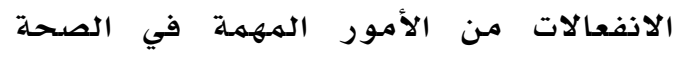
النفسية و الر فاه، لذا فإن استر اتيجيات تنظيه

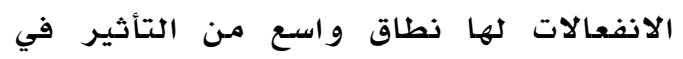
التكيف و إعادة التقييه الهعرفي، فهي تعمل

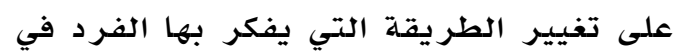
المواقف التي تثير العاطفة من أجل تغييرها،

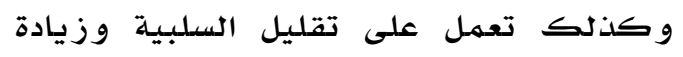

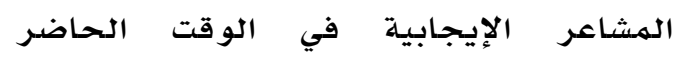
(Werner \& Cross, 2009 ; Gross \& Thompson, 2007 ;Goldin, Manber- Ball, (Werner, Heimberg \& Gross, 2009 استر اتيجيات تنظيم الانفعالات بمستويات أعلى من الإيجابية و مستويات أقل من التأثير

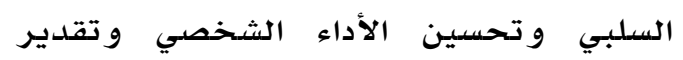
الذات و الررضا (Gross \& Tohn, 2003).

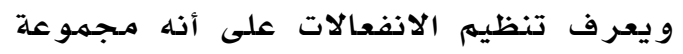

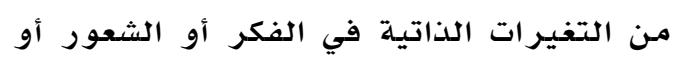

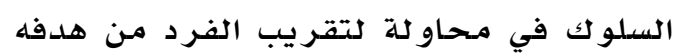
(Forgas, Baumeister \& Tice, 2009) وينظر إلى تنظيم الانفعالات على أنها

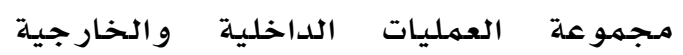

السـارة التي يواجهونها يوميا على أنها سلبيـة وخطيرة و مهددة وبالتالي يميلون إلى تفادي

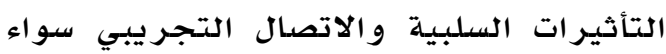
عن طريق صرف انتباههم عن المشاعر غير واتهرير السارة أو عن طريق كبت مشاعرهم. و ويقوم

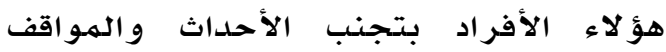

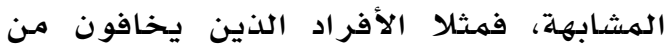
الطير ان يميلون إلى تجنب التفكير في ذلك كما سوف يتجنبون المواقف التي يكون فيها الحديث عن الطيران. و على الطرف الآخر ثمة فريق يؤمن بأن الانفعالات تتفير ويطلق

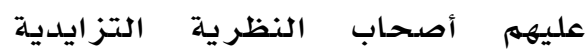
إذ ينظرون أن (incremental theory) الانفعالات قابلة للتغيير ويمكن التحكم بها و تغييرها و مثل هذه النظرة إلى الانفعالات تقود إلى تقبل الهنحنى الرئيس التنظيم

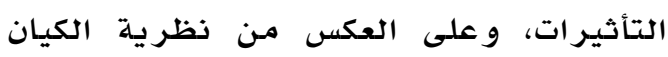

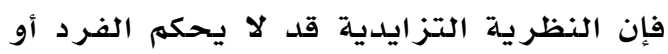
يقيهم التأثير غير السار ملى أنه سلبـي،

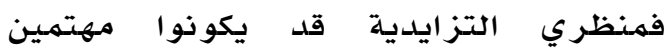

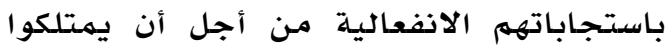

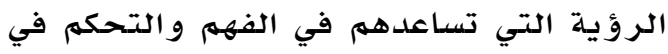
حالات الانفعال، و بالتالي إن الأحداث التي قدئ تحمل مشاعر سلبية لا ينبغي تجنبها في حد

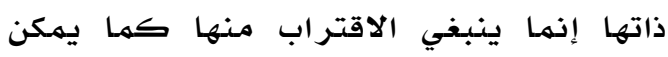

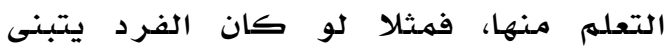

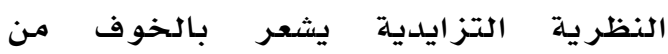
الطيران فإنه عوضا عن صرف انتباهـه عن فئه

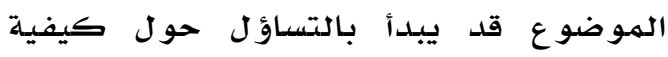

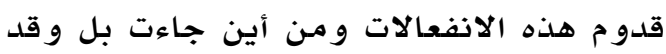
يسعى نحو فرص التعلم أكثر حول مخاوفه

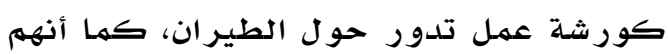
ينهمكون في تفسير الأحداث السياقية بشكل أكثر مرونة، كم أنهم يستخدمون التنظيه

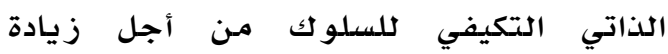
Kappes \& ) احتمالية تحقيقهم للنجاحات اجنية .(Schikowski, 2013; King \& Rosa, 2019 و نظرا لأن الاعتقادات الضمنية لها تضمينات محددة، فيتوقع أن النظريات الضمنية في

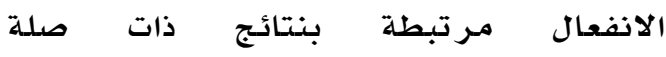


سبيل المثال من ناحية التتشيط الفسيولوجي

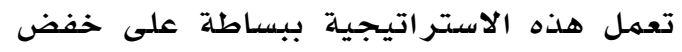
أو قهمع التعبير عن الشعور بـالانفعال .(Verzeletti et al., 2016)

تظهر العديد من الدراسـات في الأدب المتصل

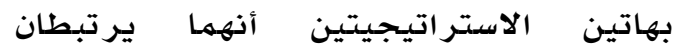

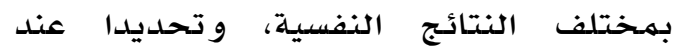
البالغين، إذ ترتبط استر اتيجية إعادة التقييهم

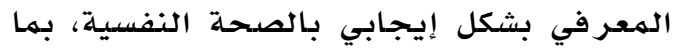
في ذلك قدر أكبر من الرضدا عن الحياة، و على العكس من ذ ذلك ترتبط استراتيجية

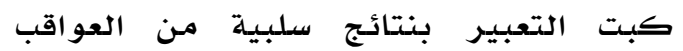

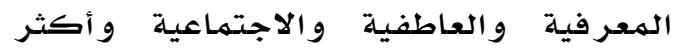

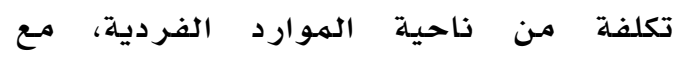

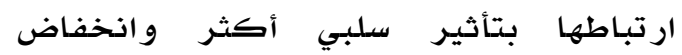

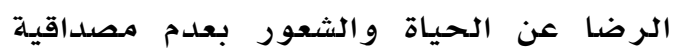

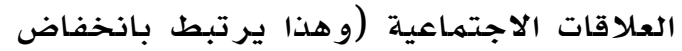

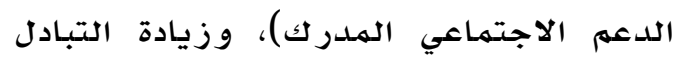

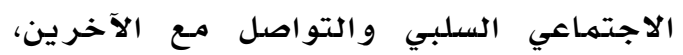

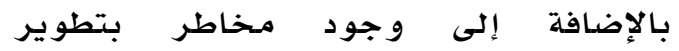
الاكتئاب و القلق ( Lebowitz \& Dovidio, ) 2015 ; Moore, Zoellner \& Mollenholt, .(2008

باختصسار هناك أدلة متزايدة على أن استراتيجيات التنظيم الانفعالي في مرحلة

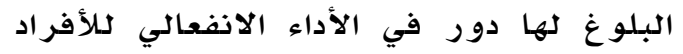
و السعادة، كما يشير الأدب النظري إلى أنى أن الن النهاء

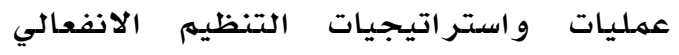

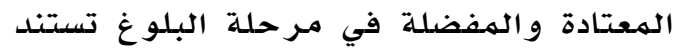

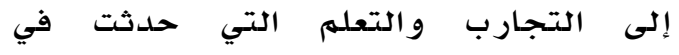

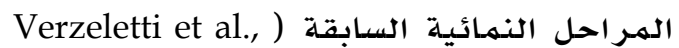

إن الأفراد القادرين على رصد وتقييه و تعديل مشاعر هم وفقا لأهدافهم هم أكثر عرضدة لتجربة السعادة، وتعد صعوبـة تنظيه

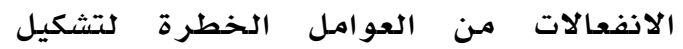

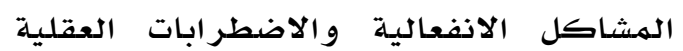

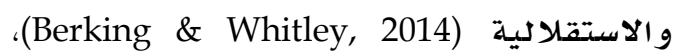
و على الرغم من توافق العلماء في تصورهم

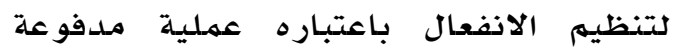

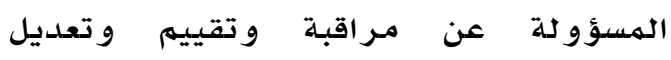

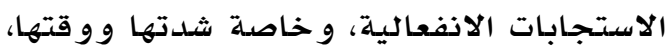
من أجل مساعدة الفرد على تحقيق أهدافه.

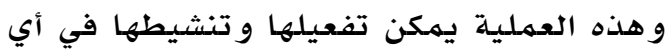
مرحلة من مر احل الاستجابة الانفعالية، من

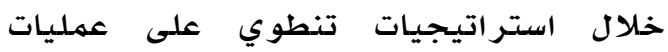
شعورية أو لا شعورية. فقد يسعى الفرد لتنظيم انفعالاته لتحسين التركيز وربالتالي لتهوريه

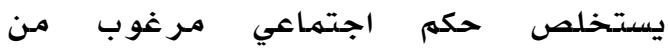
الآخرين و بالتالي استخلاص معنى للحياة

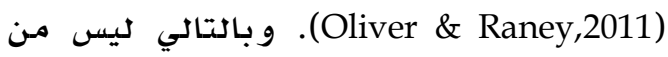
المستغرب أن يكون للقدرة على تنظيه

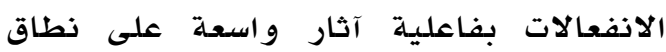

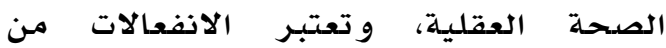

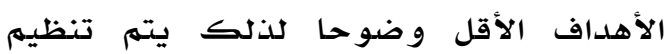
الانفعالات بهدف تحقيق الأهداف المتعلقة

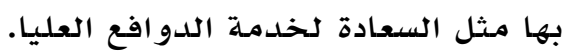
على الرغم من أنه تم اقتراح العديد من تن نماذج تنظيم الانفعالات، إلا أن النموذج النه الذي الني

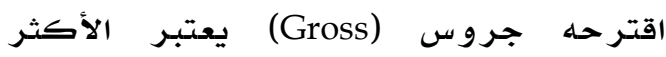

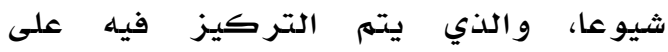
استراتيجيتين أساسيتين هما: إعادة التقييم الهـعر في (Cognitive Reappraisal) و وكبت التهين التعبير (Expressive Suppression). إعادة التقييم المعرفي بأنه استراتيجية مسبقة التركيز، وهي شكل من أشكال الشعال

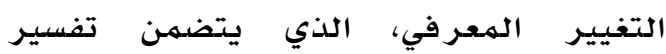
وتأويل الحالة الانفعالية بطريقة تغير

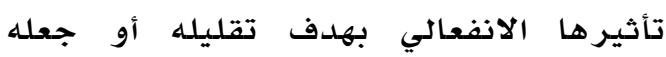
أكثر إيجابية، و يفتر ض باستر اتيجية إعادة التقييم الهمر في أن تكون فعالة في تعديل

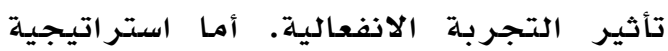

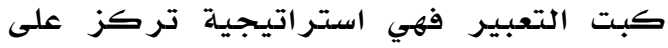
الاستجابة، و وهي شكل من أشكال تعديل

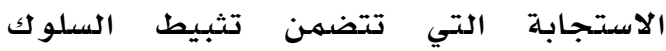

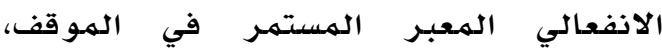
ويفتر ض بهذا التعريف أن تكون استر اتيجية

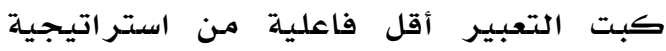
إعادة التقييم الهعرفي، ذلك أنها لا تقوم

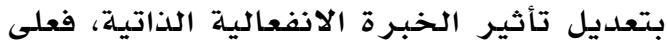


و اقتصادي أفضل، و عليه خرجت الدراسة بأن القدرة على تنفيذ استراتيجيات تنظيم

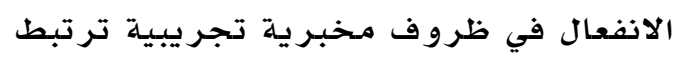
ارتباطا وثيقا بالر فاهية و النجاح المالي. Castella et al., ) و أجرى كاستيلا و آخرون 2013) دراسة هدفت للكثف عن المعتقدات حول الانفعال وارتباطها بالتنظيم الانفعالي

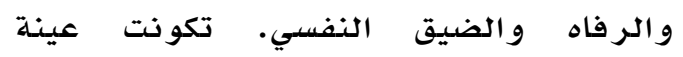

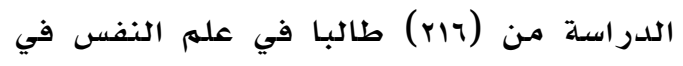

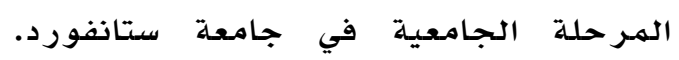
توصلت الدراسة إلى النتائج الآتية: ارتباط التاطية

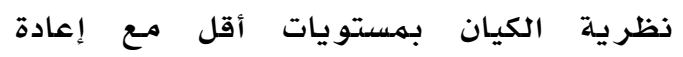

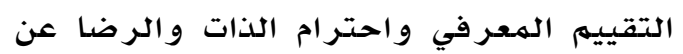

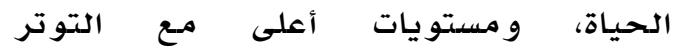

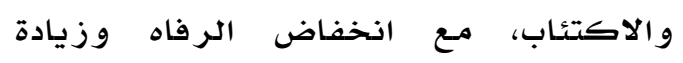

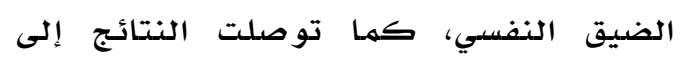

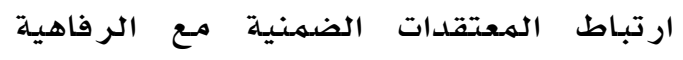

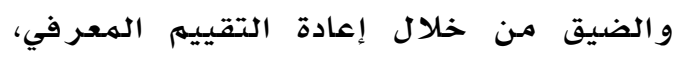

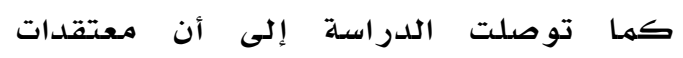

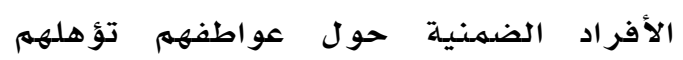

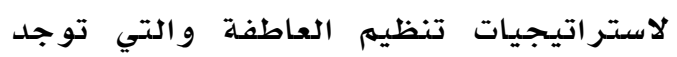
لها علاقة قوية مهمة على الصحة النفسية. و في السياق نفسه أجرى كابيس وشكوسكي (Kappes \& Schikowski, 2013) إلى الكثف عن النظريات الضمنية للانفعال

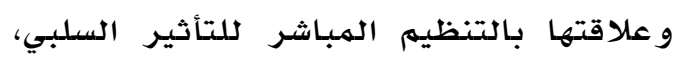

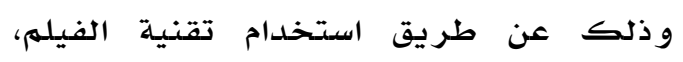

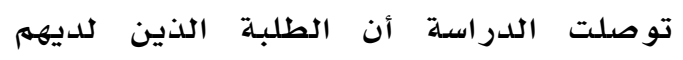

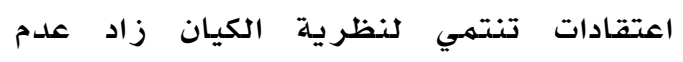

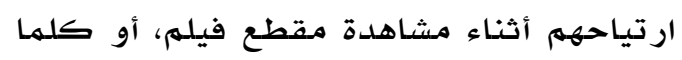

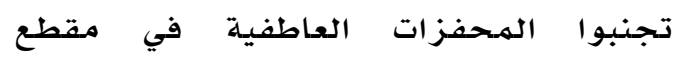
الفيديو نفسه، وبذلك تشير هذه النهات النتائج إلى الى

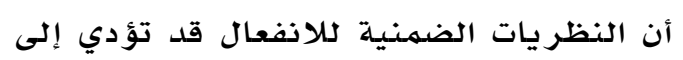

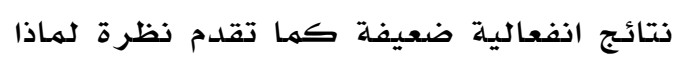

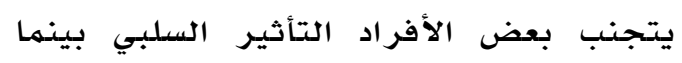

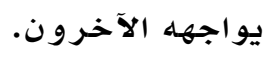

وأجرى تشين ورايكارد ) Chin \& Rickard,

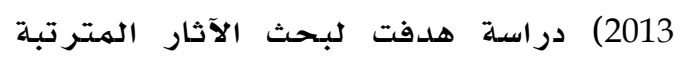
على تنظيم الانفعال (إعادة التقييم المعر في الأدي المترتية
بالهدف إلا أنه كان هناك قليلا من عمليات التحفيز والاستجابة الانفعالية المؤدية الى الى الى التكيف (Tamir, 2016). تستحوذ دراسة السعادة على اهتمام بالغ من

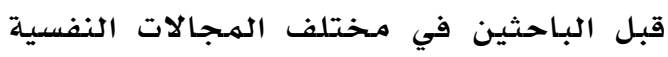

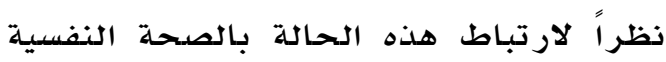

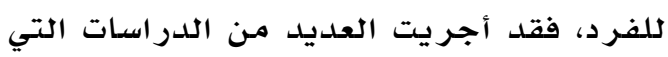

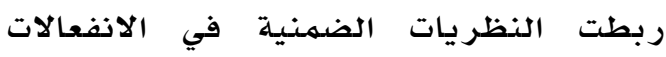

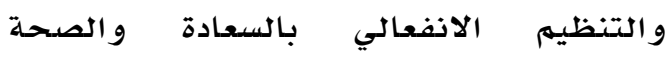

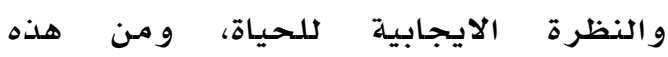

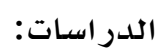

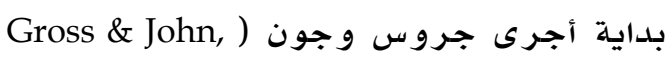
2003) التي تستند إلى افتراض اضن أن الأفراد

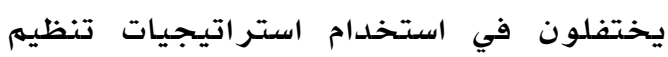

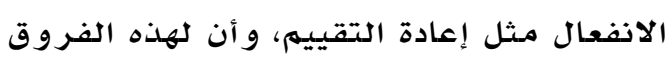

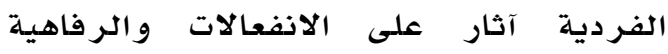

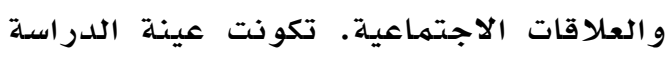

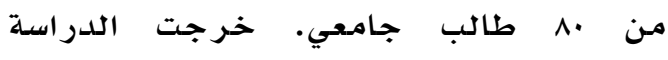

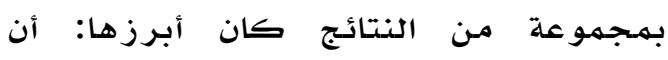

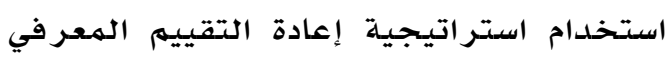

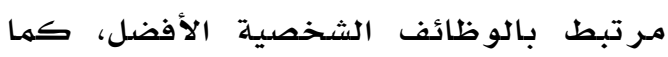
أنها تر تبط ارتباطا إيجابيا بالر فاهية. كما أجرى كوتي وجيراك و ولييفنسون (Cote, Gyurak \& Levenson, 2010) هدفت إلى دراسة العلاقة بين الفروق

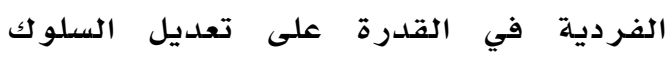

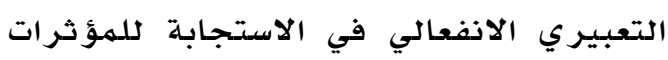

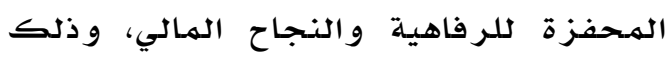

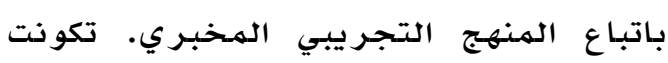

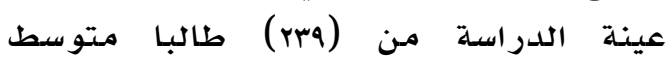

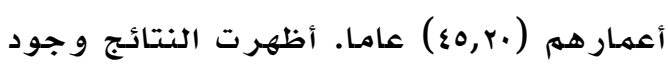

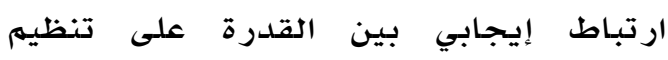

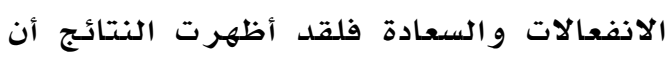

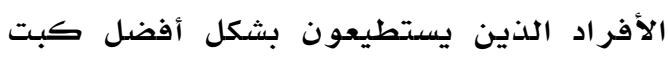

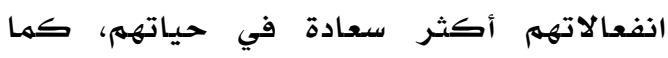

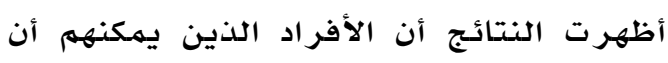
يكونوا أفضل في تضخيه ردود النتانج أن الافراد الفين لفعالهم حيال

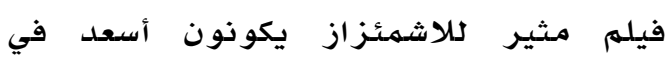

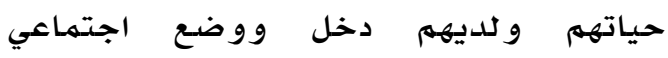


بشكل إيجابي مـع معظم مؤشر ات السعادة، و لا

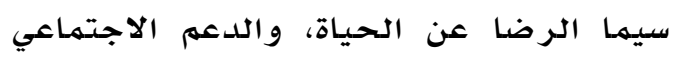

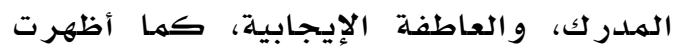

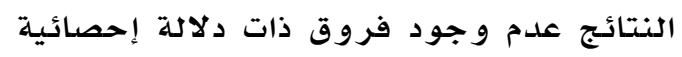

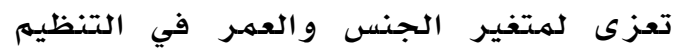
الانفعالي وكبت التعبير ، كما أظهرت نتائج الدراسـة ثمة فرق يعزى لمتغير الجنس في

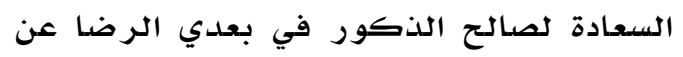

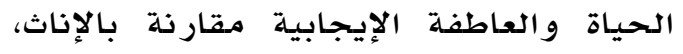
كما تشير النتائج الإجمالية أن النهاهية السعادة

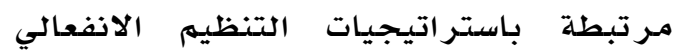
المفضلة.

و في نفس السياق أجرى كاستيلا ( Castella,

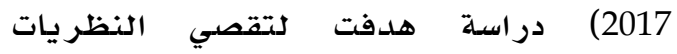

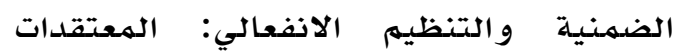
الانفعالية وعلاقتتها بالصحة النفسية و الر فاه

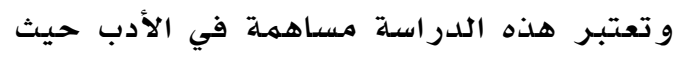

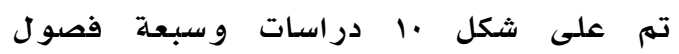
تجريبية لفحص الارتباط بين النظريات

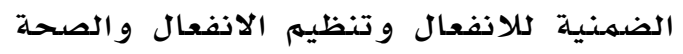

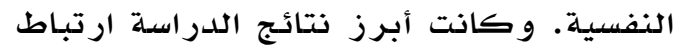

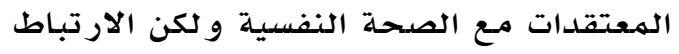

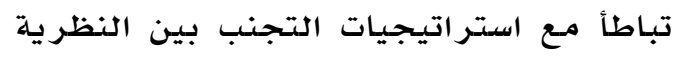

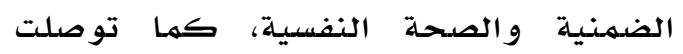

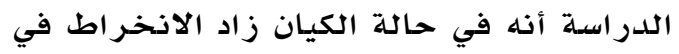

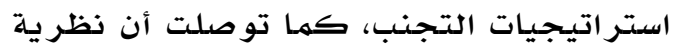

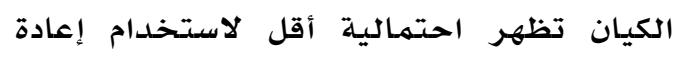
التقييم المعر في في الحياة اليوميلة.

وأجرت مومني (Moumne, 2017) دراسة هدفت للكشف عن منظور النظرية الضمنية على تنظيه الانفعالات. تكونت عينة الدراسـة

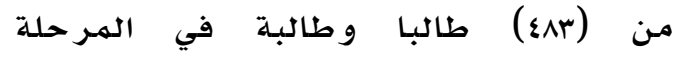

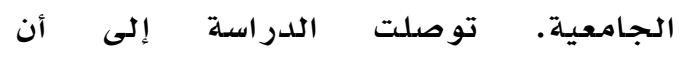

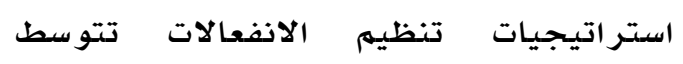

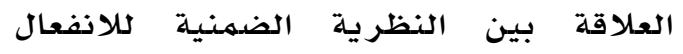
والأداء النفسي (الرفاه).

و في دراسة كاستيلا وبلاتو وتامر وجروس (Castella, Platow, Tamir \& Gross, 2018) سعت لبحث الآثار المتر تبـة على عدم القدرة

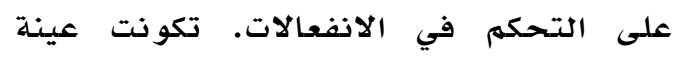

و الكبت) في العلاقة بين الانهماك الموسيقي

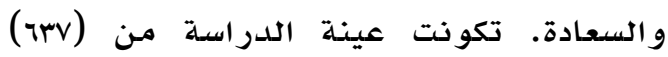

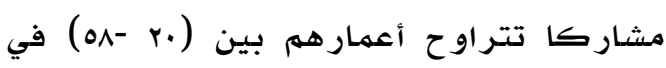

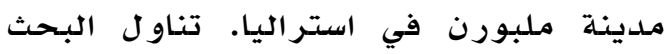

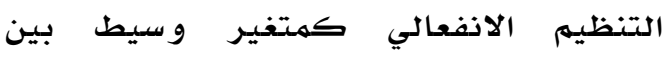
الرفاهية النفسية والانهماك الموسية الانيقي الذي تم تناو له كمتغير خارجي مستقل. أظهرت

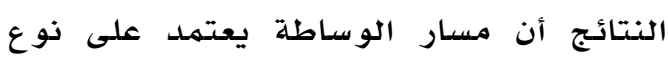

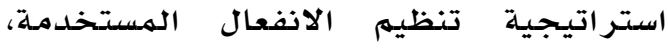
وكذلك الطريقة التي يتفاعل بها الفرد مـع

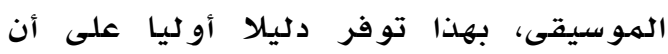

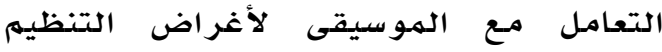

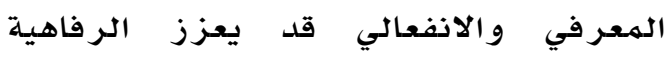

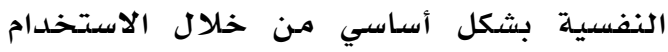

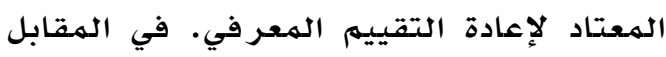

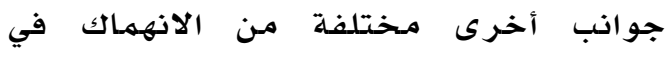
الموسيقى (الاستمـاع إلى الموسى النيقى و الإنتاج

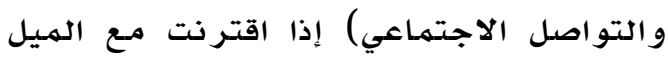

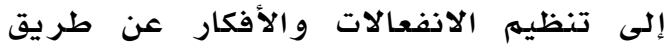
استر اتيجية الكبت التعبير التي يؤدي إلى تحقيق رفاهية غير مرغوب بها. و عليه تسلط هذه

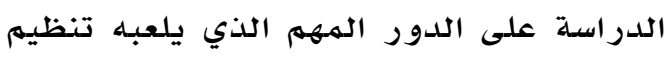

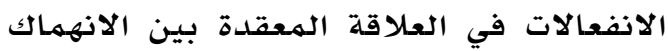

$$
\text { الهموسيقي و السعادة. }
$$

Asadi et al., و في دراسـة آسادي و آخرون

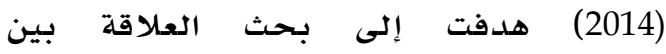

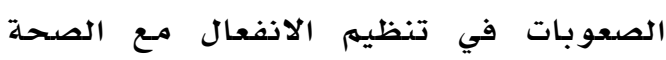

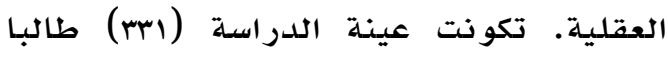

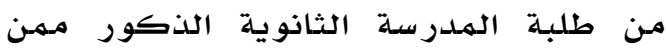

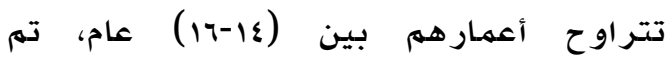
اختيار ها بالطريقة العنقودية. أظهرت النتائج وجود علاقدة ذات دلادة إحصائية بين

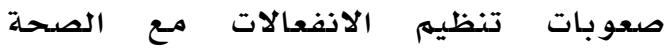
العقلية.

كما قام فيرزليتي و آخرون ( Verzeletti et

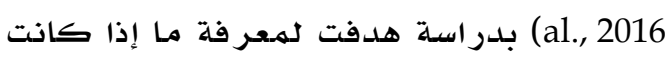

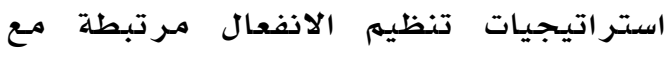

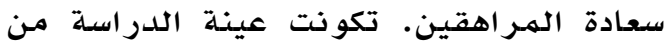

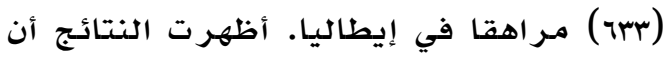

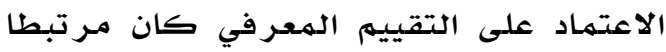




$$
\begin{aligned}
& \text { استراتيجيات التتظيم الانفعالي تتوسط }
\end{aligned}
$$

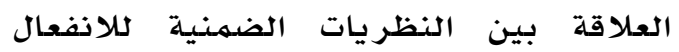

$$
\begin{aligned}
& \text { و الأداء النفسي (الر فاه). }
\end{aligned}
$$

كما يلاحظ من خلال الدّراسـات السابقة عدم

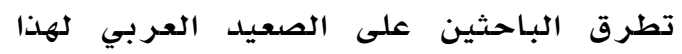

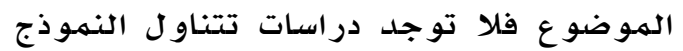

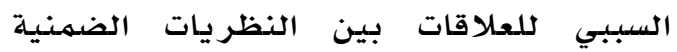

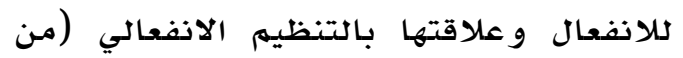

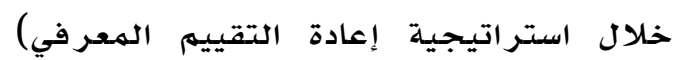

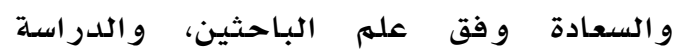

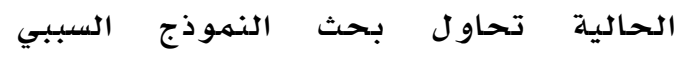
للعلاقات بين النظريات الضمنية في الانفعال

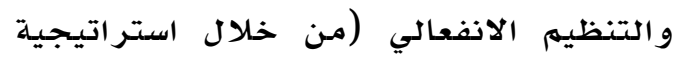

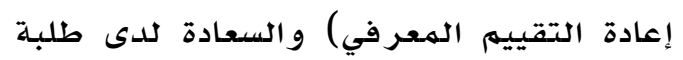

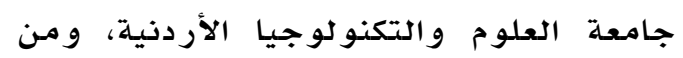

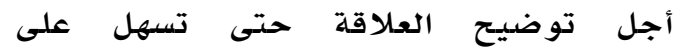

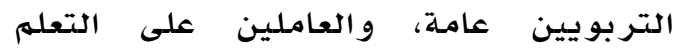

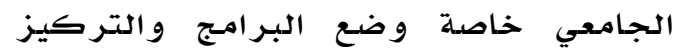
على علم النفس الإيجابي بأفضل شكل مـكن.

\section{مشكلة الدر اسة و أسئلتها}

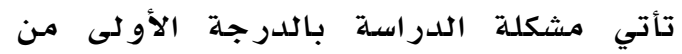

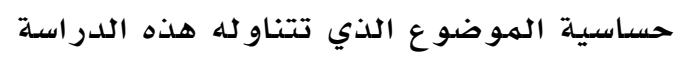

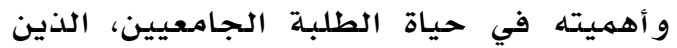

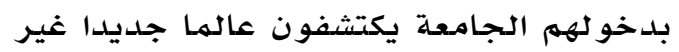
مألوف بطبيعته، و أنهاط العلاقات الاجتمهاعية السائدة فيه، وضغط الدر اسلة وظروف الحياة

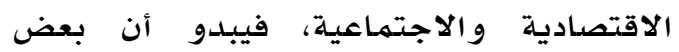

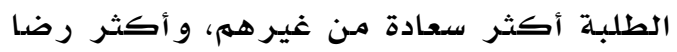

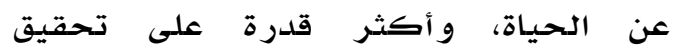
أهدافهم. وبالتالي هذا يحتم على الباحثين النظر في طبيعة العوامل المؤثرة في تحقيق السعادة.

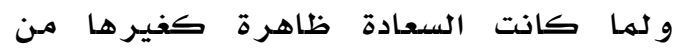
الظواهر النفسية التي تمتاز بالتعقيد وو جوداد الكثير من العوامل الهسؤولة عن تحقيقها،

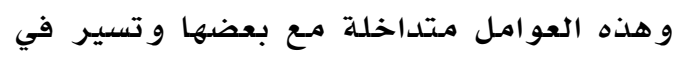
نهط مـن علاقات التأثير والتأثر لتشكل في

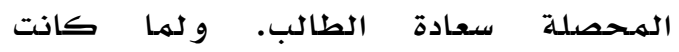
الانفعالات التي نشعر بها ونعبر عنها مهمة
الدراسة من (III) فردا. أظهرت النتائج أن نقص القدرة في التحكمم بالانفعالات يتنباً بنتائج صحية ضعيفة كانخفاض الرفاهية

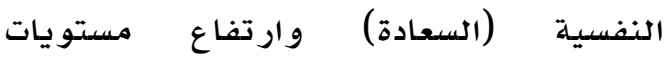
الأعر اض السرير يـة السية.

أجرى كنج وروز1 (King \& Rosa, 2019)

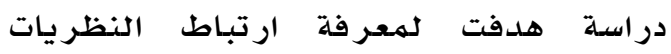

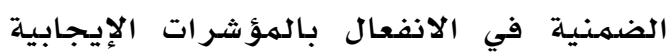
و السلبيية للرفاه من خلال إعادة التقييم

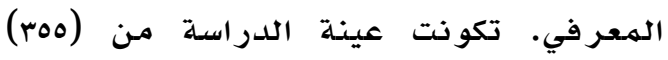
طالبا من جامعة الفلبين. توصلت نتائج

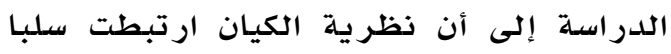
بالرفاه، كما أنها تنبأت سلبـا باستخدام إعادة إنهات التقييم المعر في في حين ارتبطت إيجابيا مـع

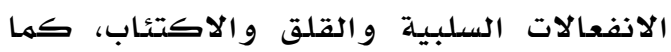

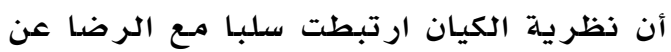
الحياة والانفعالات الإيجابية.

و بعد استعر اض نتائج الدراسـات السابقة لوحظ أنها تناولت الأثر المباشر لنظر الترية

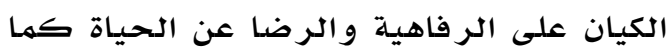

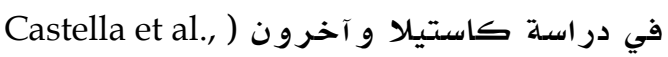
2013) ودراسة كابيس وشكو سكي ( Kappes

.(\& Schikowski, 2013

كما يلاحظ أن نتائج الدراسـات السـابقة لهم

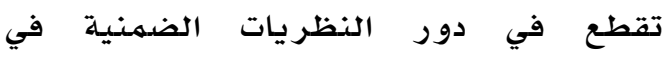

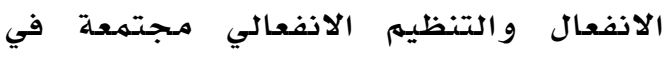
تحقيق السعادة، كما أظهرت دراسـة كل من آدئ

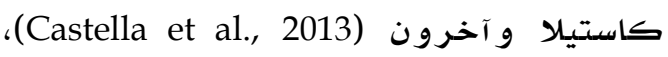
و دراسدة كاستيلا (Castella, 2017) ارتبرنياط

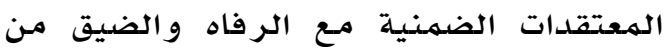
خلال إعادة التقييهم المعرفي، إذ أن نظريه إنهاه

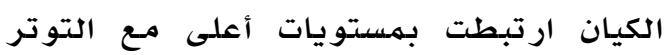

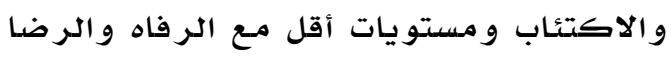

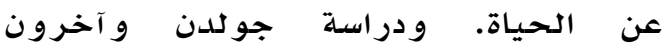
(Goldin et al., 2013)

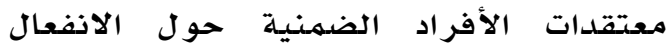

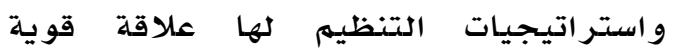
بالصحة النفسية. أما في ما يخص ديله دراسـة

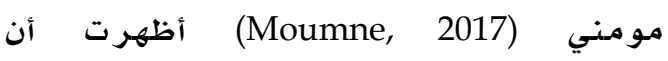


المتغيرات ووضع نموذج سببي يوضح

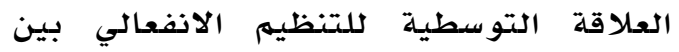

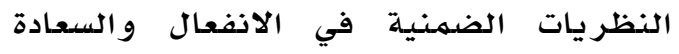

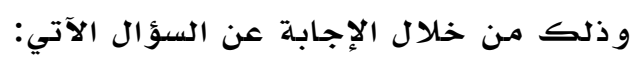

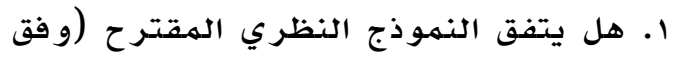

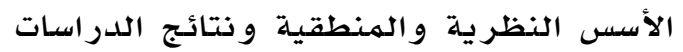

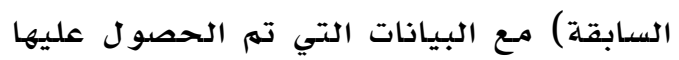

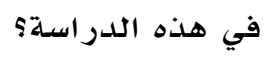

أهمية الدراسة

أهميـة نظرية: تنبـع أهمية الدراسـة الحالية

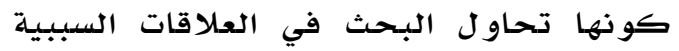
بين تنظيم الانفعالات وفق استراتيجية إعادة

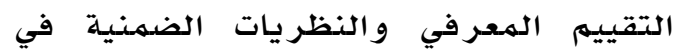
الانفعال في تحقيق السعادة الأمر الذي الذي يعد الديد

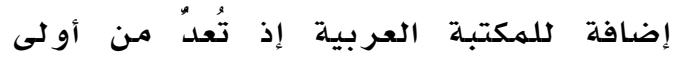

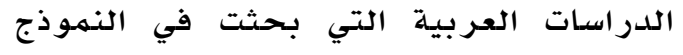

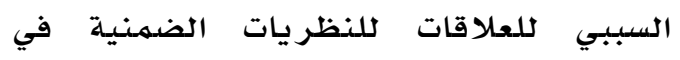
الانفعال و التنظيم الانفعالي و فق استر اتيجية

إعادة التقييم المعر في و السعادة مجتمعةً. أهمية تطبيقية: تتمثل في الإفادة من نتائج

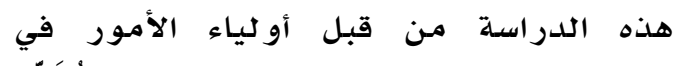

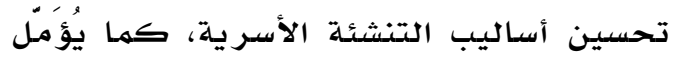

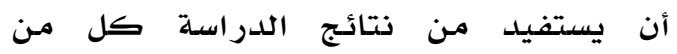

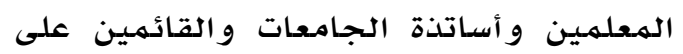
تخطيط وتنفيذ البرامـج التعليميلة من أجل ولهيل تطوير أساليب ووسائل تعليمية و وتطوير

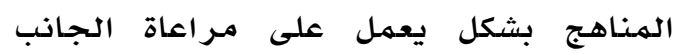
الانفعالي و إعادة التقييم المعر في في سبيل تحقيق السعادة.

محددات الدر اسة وحدو دها يتحدد تعميهم نتائج هذه الدراسة بعينة

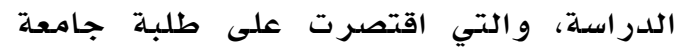

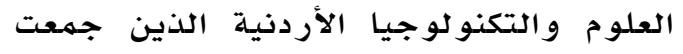
بيانات الدراسة منهم خلان الدان الفصل الدراسيا

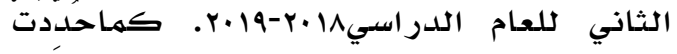
نتائج هذه الدراسة بالأدوات التي استخدمت التئي

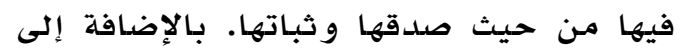

جدا لسلامتنا وسعادتنا النفسية و الجسدية، مثثلا قد تعزز تحقيق الأهداف و وتسهل

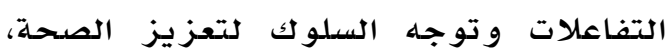
و مـع ذلك لا تكون المشاعر المحسوسة دائما و ظيفية و تكيفية (Verzeletti et al., 2016). ذلك أن ما يرتبط بهذه الانفعالات من ونديه اعتقادات تأخذ دورها في التأثير على سعادة الأفراد فاعتقادات الفرد حواد لتود الانفعالات تم تنظييهها في النظريات الضمنية في الانفعال.

ورغم أهمية دور النظريات الضمنية في

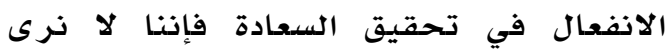

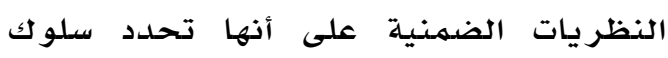

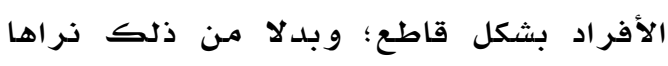
كإنشاء إطار عمل يتم فيها تعزيز الأحكام وردود الفعل المتسقة مـع ذلك الإطار أيضا،

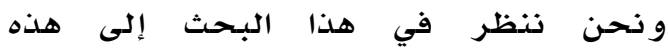
النظريات ببساطة على أنها طرق متغيرة

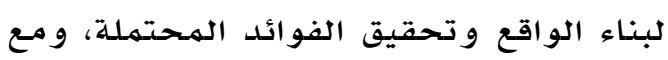
العلهم أن البحث ليس لتقييم صدحة النظريتين

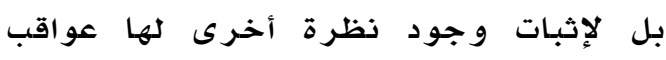

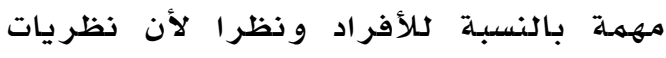

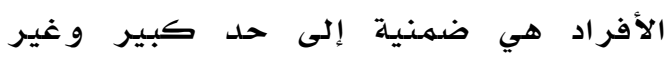

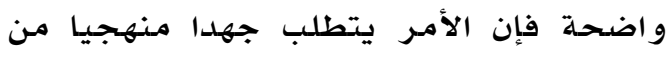
جانب علماء السلوك لتحديدها و وتحديد

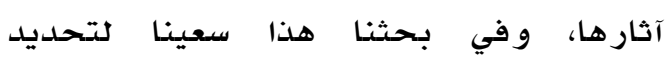

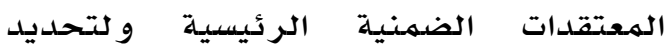

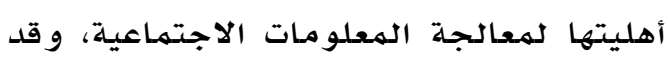
كان هذا البحث لتحديد النظريات الضمهنية التي نعتقد أنها و وضعت كإطار لتحليل

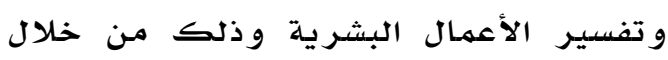

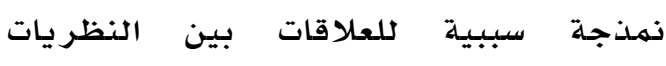

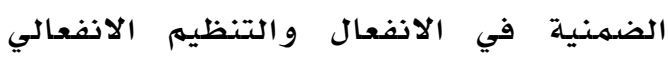

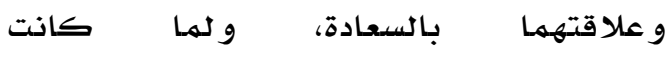

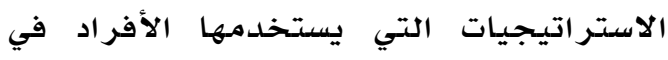

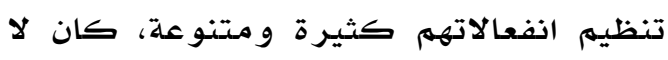
بد من تناول استر اتيجية التقييم الهعرفي،

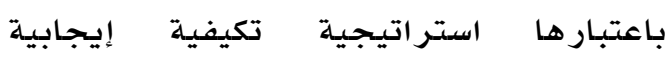

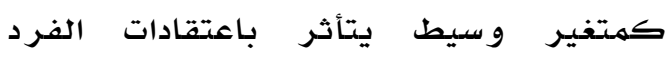

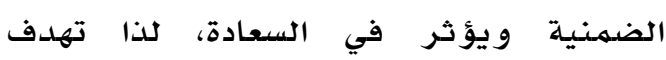

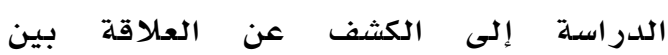


السعادة

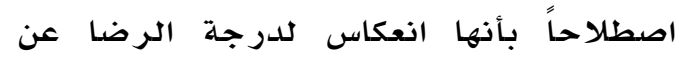

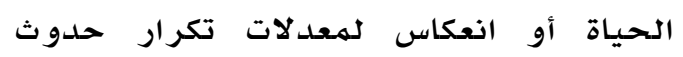

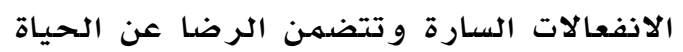

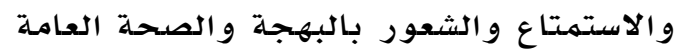

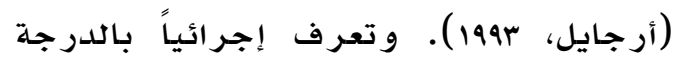

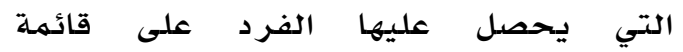
أكسفورد (Oxford) للسعادة التي تحتوي على جو فقرة.

\section{الطريقة والإجر اءات}

\section{مجتمع الدر اسة}

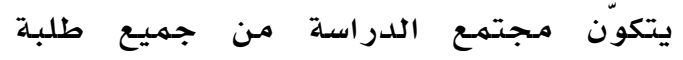

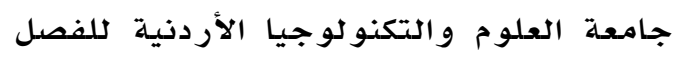

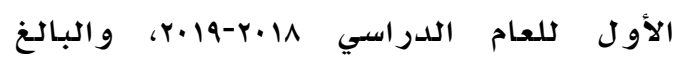
عددهم حسب إحصائيات عمدادة القبول و التسجيل (وس.7r) طالباً و طالبة، تهم استثناء آدهاء

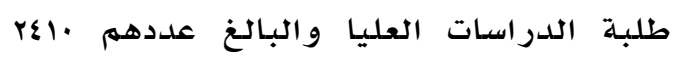

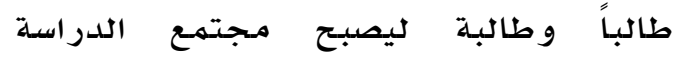

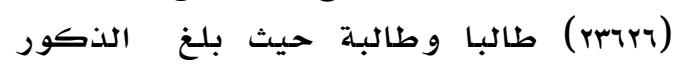

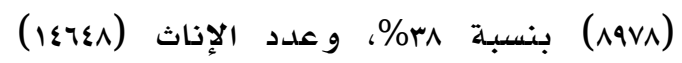

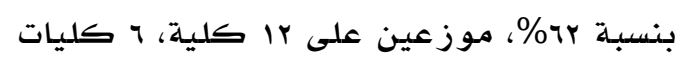

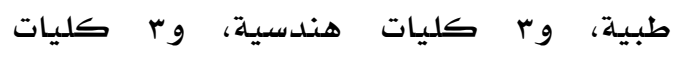

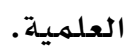

\section{عينة الدراسة}

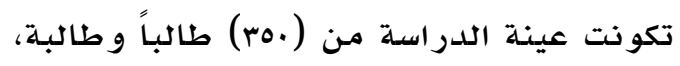

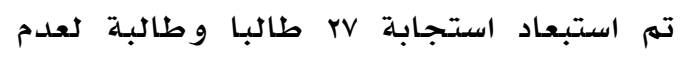

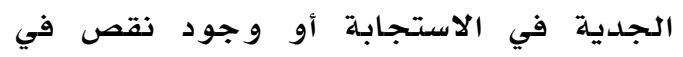

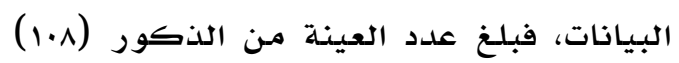

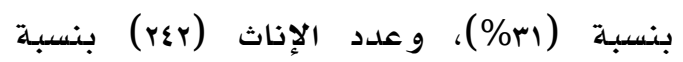

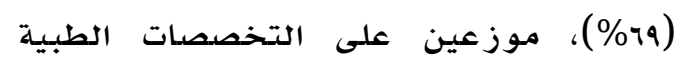

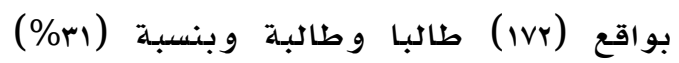

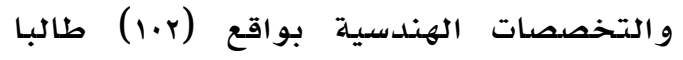

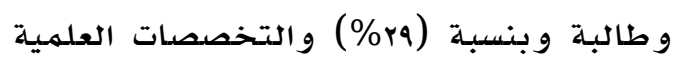

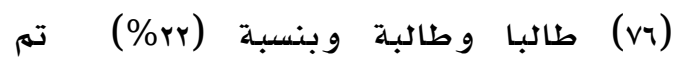
اختيارها بالطريقة المتيسرة وكانت وحدة ولدة ولهابة الاختيار هي الشعبـة.
الهنهج الذي استخلدمـه الباحثين وهو الهنهج الوصفي التحليلي.

أما حدود هذه الدراسـة فهي الحدود البشرية،

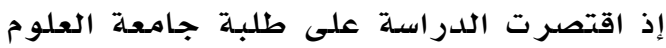

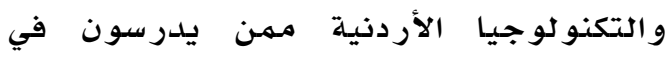

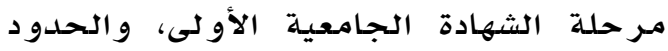

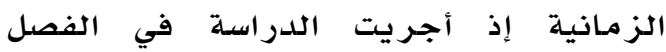

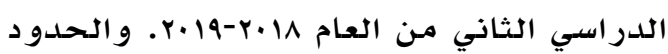

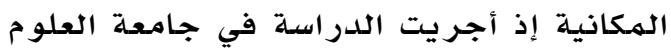
و التكنو لوجيا الأردنية التي تقع ضهمن إدئ مدينة

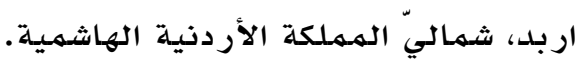

\section{التعريفات الاصطلاحية والإجر ائية}

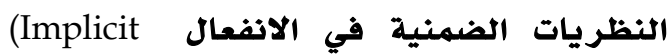
:Theories of Emotion)

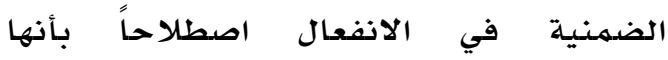

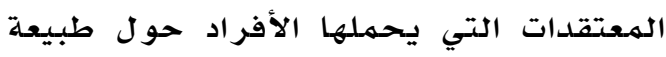

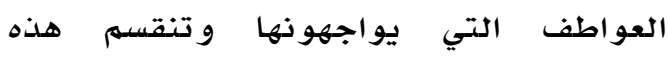
المعتقدات إلى منظورين المنظور الأول

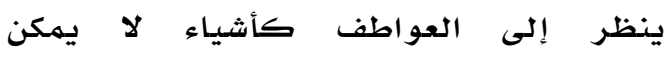
السيطرة عليها ويسهى هذا المنظور بنظرية الكيان، والمنظور الثاني ينظر إلى أن الأفر اد يستطيعون تعلهم التحكم بعواطفهم و تنظيهها

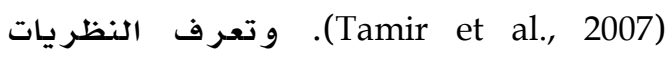

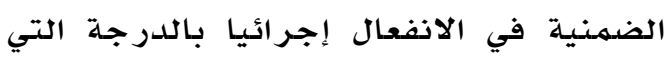
يحصل عليها الطالب على مقياس النظريات

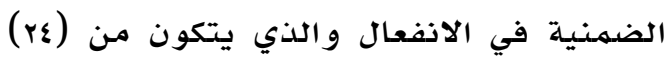
فقرة موزعة بالتساوي على بعدين: نظريـة الكيان و النظرية التز ايدية.

التنظيم الانفعالي (Emotion Regulation): يعرف التتظيم الانفعالي اصطلاحًا بأنه استراتيجيات متضمنة إعادة طبيعة الأفكار و السلوكيات التي تؤثر في الانفعالات التي يمتلكها الفرد و والسيطرة عليها و وكيفية الإفصاح عنها لاحقا (Castella et al., 2018)

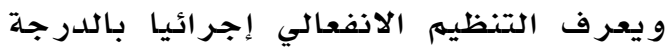

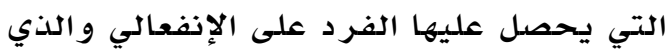
يحتوي على (7) فقر ات . 


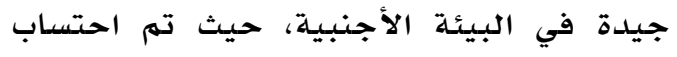

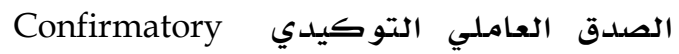
Factor Analyses (CFA) أظهرت النتائج أن أعلى صدق هو عندما تم

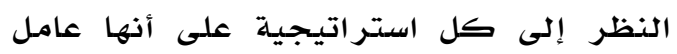

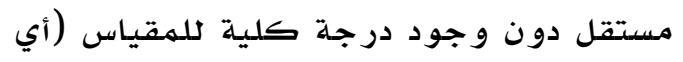

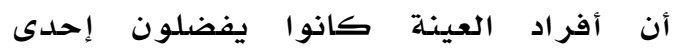

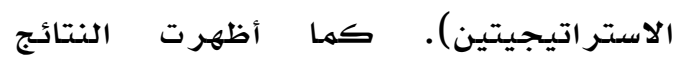
ملائمسة مؤشر ات المطابقة بحصو لها على قيم

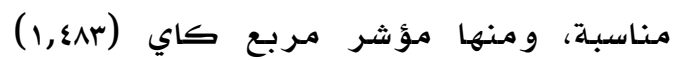

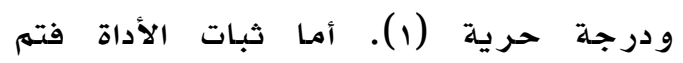

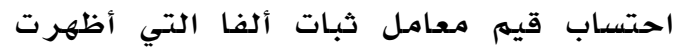

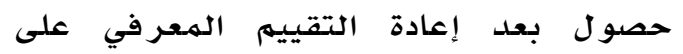

$$
\text { القيمهة (V), •). }
$$

إجر اءات الصدق والثبات في الدر اسلة الحالية:

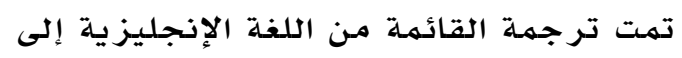

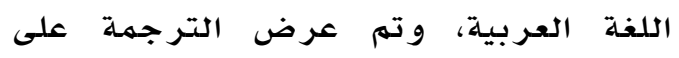

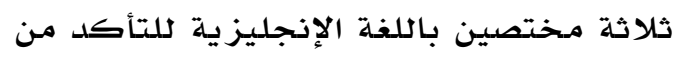
سلامتها. ثم تهم إجراء تر جمهة عكسية للقائمهة

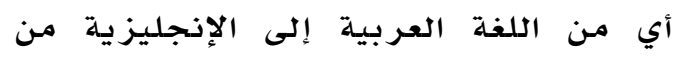

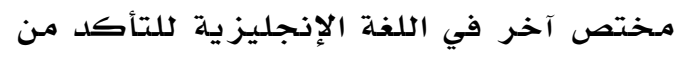

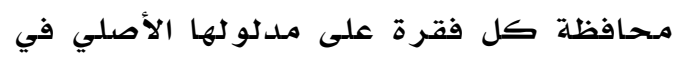

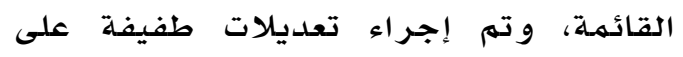
النص العربي في ضوء هذه الإجراءات إجراء كما

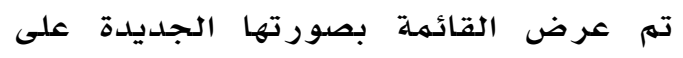

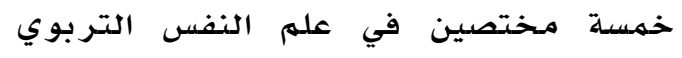

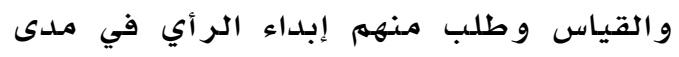
انتماء كل فقرة إلى البعد الذي تقيسه وقد الذه

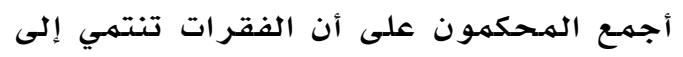

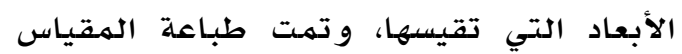
في صورته النهائية. أما بالنسبة لإجراءات صدق البناء تم تطبيق

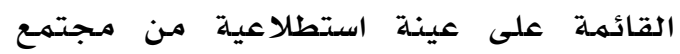

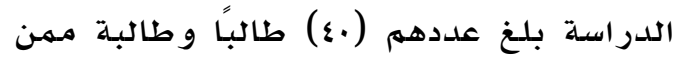
يدرسون أحد مساقات متطلبات الجامعبة، و بعد ذلك تم حساب معاملات ارتباط فقرات

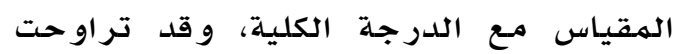

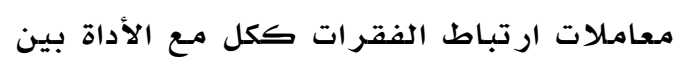

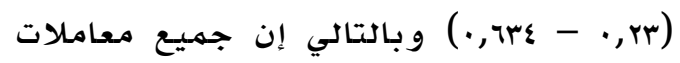

\section{منهجية الدراسة}

تَمَّ اتّباع المنهج الوصفي بشقيّه الارتباطي

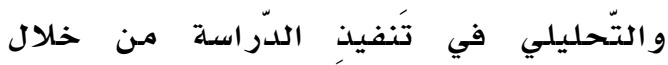
توظيف أسلوب تحليل المسار، الذي يتناول

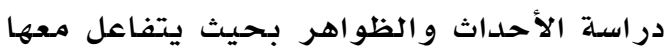

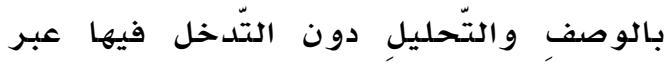

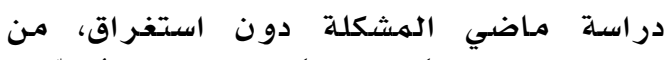

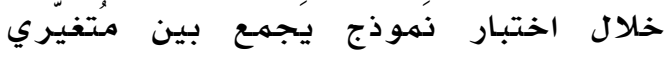

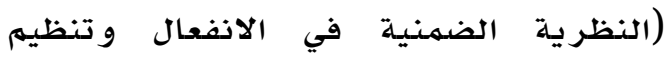

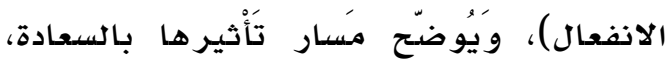

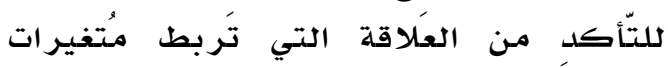

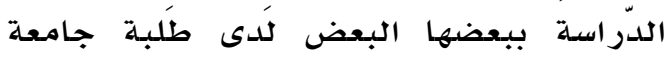
العلوم و التكنو لوجيا. أدوات الدراسة لتحقيق أهداف الدراسة تم استخدام ثلاث

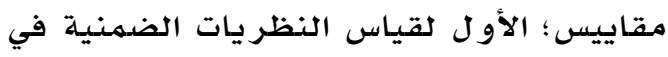

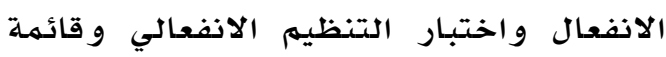

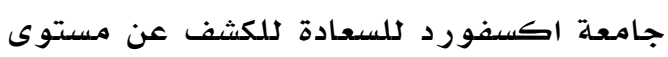
السعادة لدى أفراد عينة الدراسلة.

أولاً: مقياس التنظيم الانفعالي ( Emotion :(regulation

وضعه أصلاً جروس وجون ( Gross \& John,

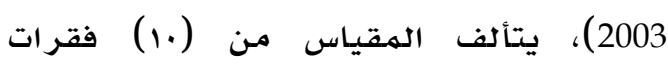
موزعة على استراتيجيتين هما إعادة التقييم

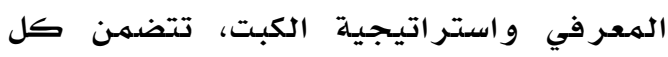

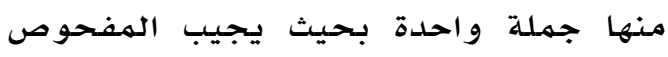

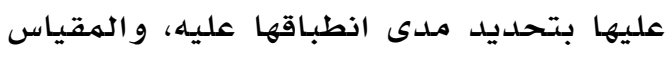
من نوع ليكرت وهي ذات تدريج الخمـاسي

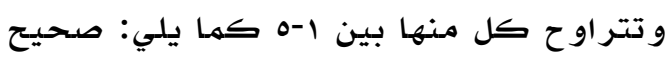

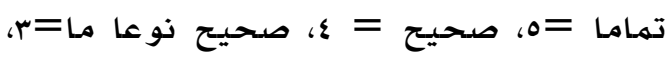

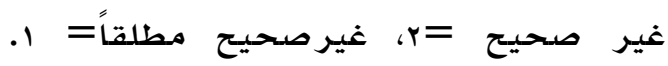

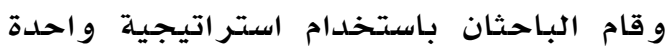

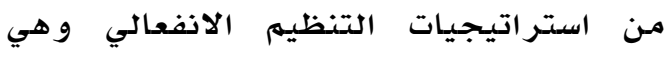
استر اتيجية إعادة التقييم المعر في و وكان

$$
\text { عدد فقر اتها (7) فقر ات. }
$$

إجراءات الصدق والثبات الأصلي للمقياس إجراءات الصدق و الثبات الأصلي للقائمـة:

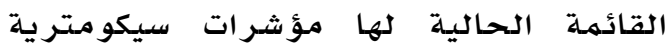


محافظة كل فقرة على مدلو لها الأصلي في

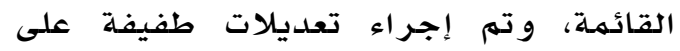

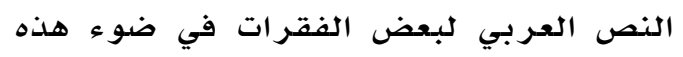

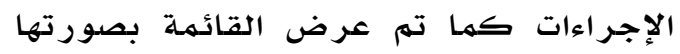
الجديدة على خمسة مختصين في عله النفس التراء

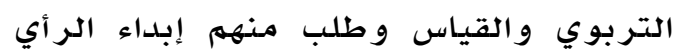

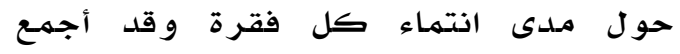

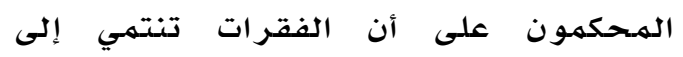
القائمسة و تم طباعتها.

أما بالنسبة لإجراءات الصدق و والثبات تم

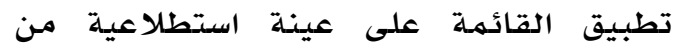

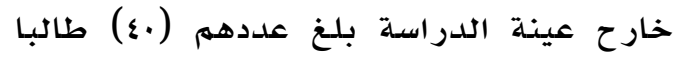
و طالبـة مـمن يلدرسون أحد مساقات متطلبهات

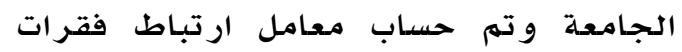

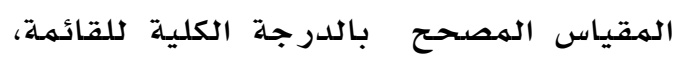

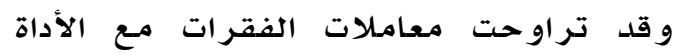

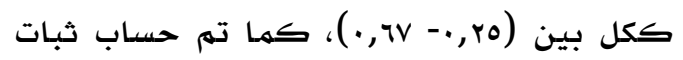
الاتساق الداخلي( كرونباخ ألفا) و ومعامل ارتباط بيرسون بين تقديراتهم في المـرتين (test-retest)

$$
\text { ه9, • ( ) على التوالي. }
$$

ثالثا: مقياس المعتقدات الضمنية للانفعال (Implicit theories of emotion)

Livingstone, ) وضعه أصداً" ليفينجستون

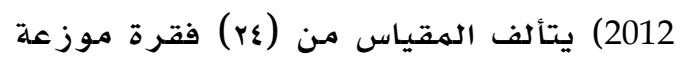

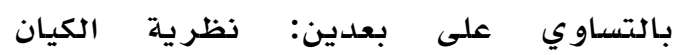
و النظرية التزايدية تتضمن كل منها جملة واحدة بحيث يجيب المفحوص عليها بتحلديد

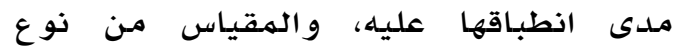
ليكرت ووهي ذات تدريج خماسي و وتتراوح كل منها بين ا-ه كما يلي: صحيح تماما

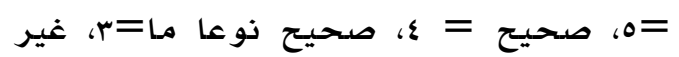

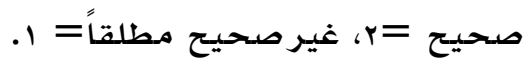

حيث تم احتساب معامل صدق البناء عن

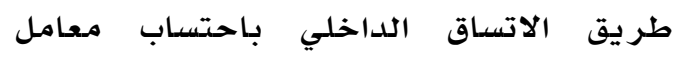

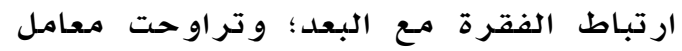

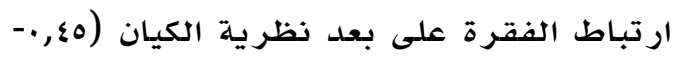

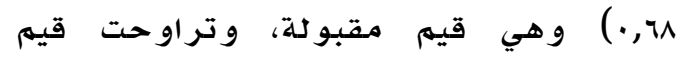

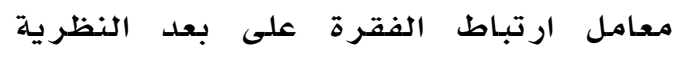

الارتباط الهصححة كانت أكبر من معيار

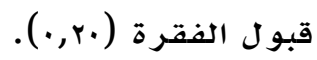

كما تم حساب شبات الاتساق الداخلي

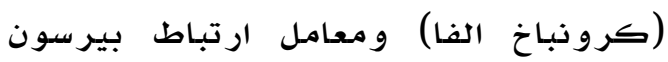

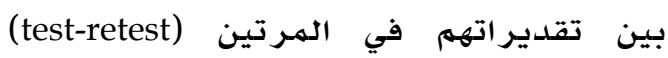

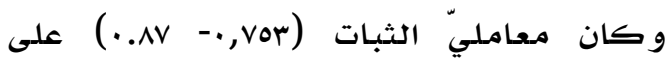

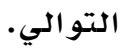

Oxford (OHI)) قانياً: ائمة (Happiness inventory

Argyle, (القائمسة أصلاً لأرجايل و مار تن و لو (martin \& Lu, 1995

Oxford Happiness أكسفورد للسعادة

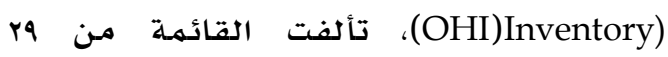
فقرة تتضمن كل منها جملة واحدة بحيث

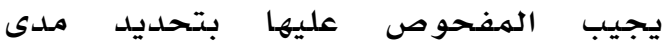

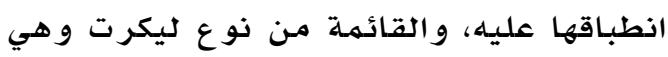

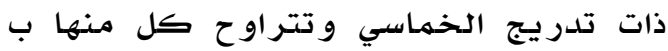
بين ا-ه كها يلي: صحيح تهاما = ه، صدحيح \&=

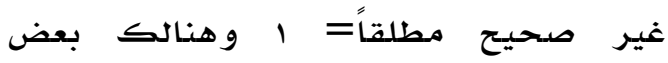

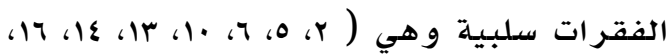

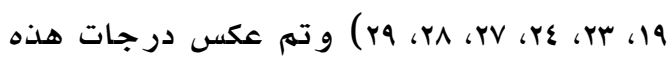

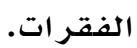

إجراءات الصدق و الثبات الأصدي للقائمـة:

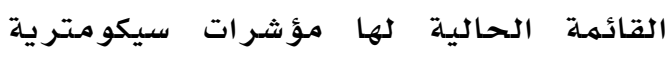
جيدة في البيئة الأجنبية، فبعد تطبيقها على الى

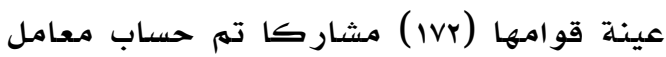

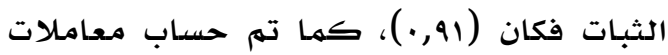

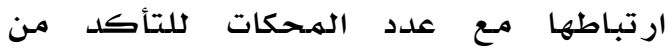

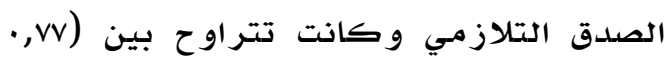

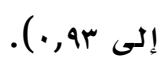

إجراءات الصدق والثبات للدراسـة الحالية:

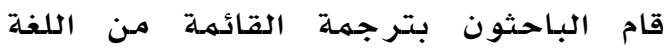

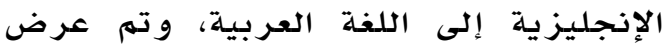

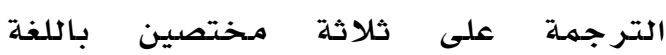

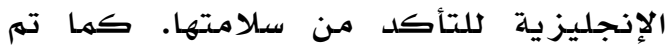

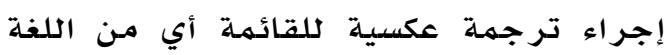

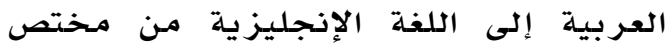

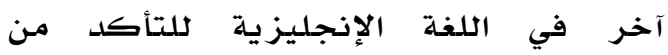




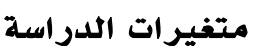

تضمنت الدراسة المتغيرات المستقلة التالية

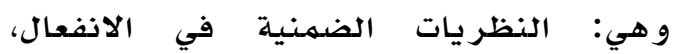

التنظيم الانفعالي النطريات

المتغير ات التابعة: السعادة.

\section{نتائج الدراسة}

سيته عرض النتائج وفق أسئلتها على النحو

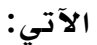

السؤال الأول هل يتفق النموذج النظري المقترح (وفق الأسس النظرية والمنطقية

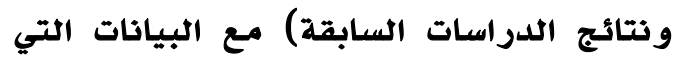
تم الحصول عليها في هذه الدراسة؛ للإجابة عن هذا السؤال استخدم أسلوب تحليل المسار (Path Analysis)، واختبار

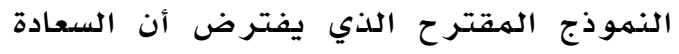

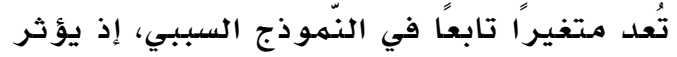

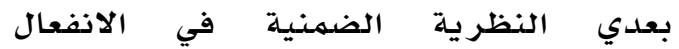

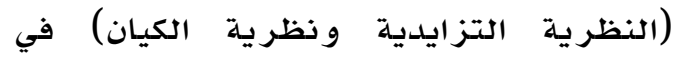

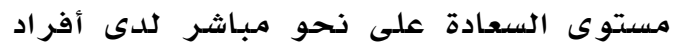
عينة الدراسة، وكذلك فإن النهوذج يتضمن النهادة

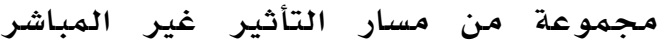
لتأثير بعد النظرية الضمنية في الانفعال

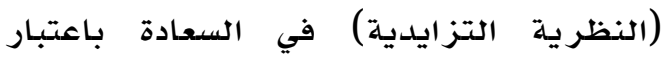

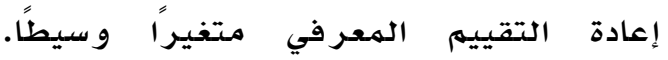
و يوضح الشكل 1 الرسم التوضيحي للنموذ الهع. وللتحقق من مطابقة النهوذج الهقترح

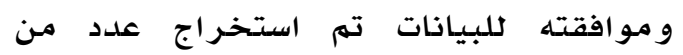

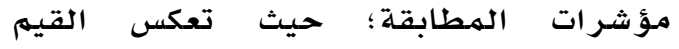
المقاربة لقيه (1) أو التي تزيد عن (.9, (·)

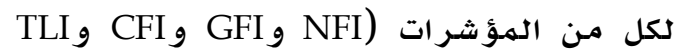

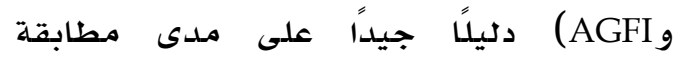

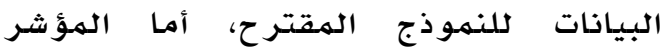
(RMR)

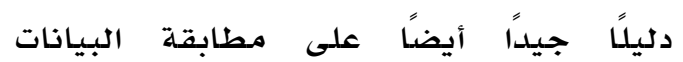
للنموذج الافتراضي (Khine, 2013 ؛ لعون اضيلان

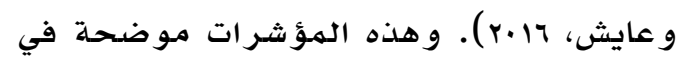

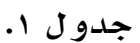

المتدرجة (rا,.-- VI, ) ) وهي قيم مرتفعة

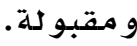

وقد تم احتساب معامل ثبات الإعادة

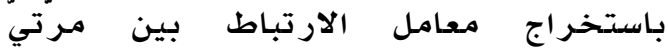

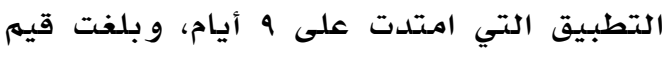
ثبات الإعادة (ه9, •).

إجراءات الصدق و الثبات للدراسة الحالية:

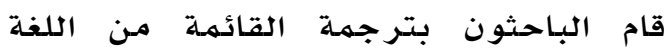

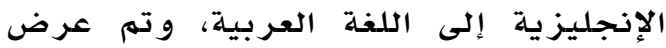

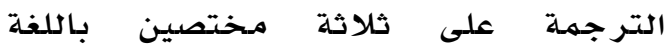
الإنجليزية للتأكد من سلامتها. كمها تم إجراء ترجمة عكسية للمقياس أي من اللغة الغية

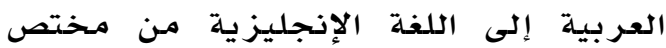

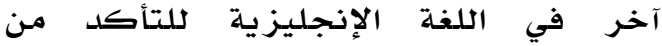

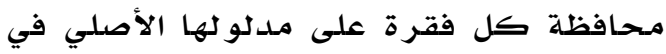
المقياس، وتم إجراء تعديلات طفيفة على هلى

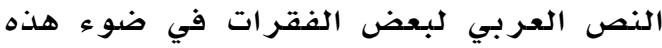
الإجراءات كما تم عرض المقياس بصورته الجديدة على خمسة مختصين في علم النفس النس التربوي والقياس وطلب منهم إبداء الرأي

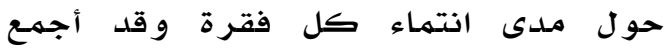

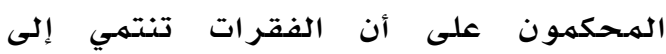
المقياس.

أما بالنسبة لإجراءات الصدق و الثبات تم تطبيق المقياس على عينة استطلاعية من الاجراء المات

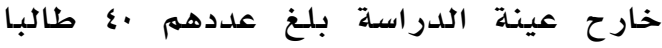

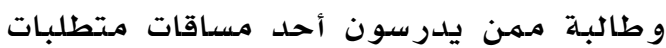

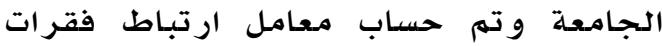

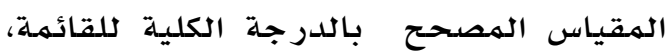
وقد تراوحت معاملات ارتباط الفقرة على

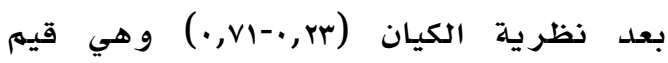
مقبو لة، وتر اوحت قيم معامل ارتباط الفقرة

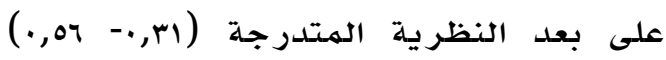

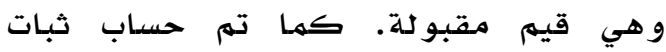
الاتساق الداخلي (كرونباخ ألفا) و ومعامل

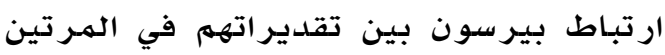

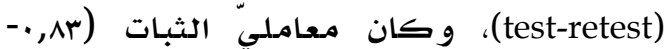
זي, • ) على التو الي. و 


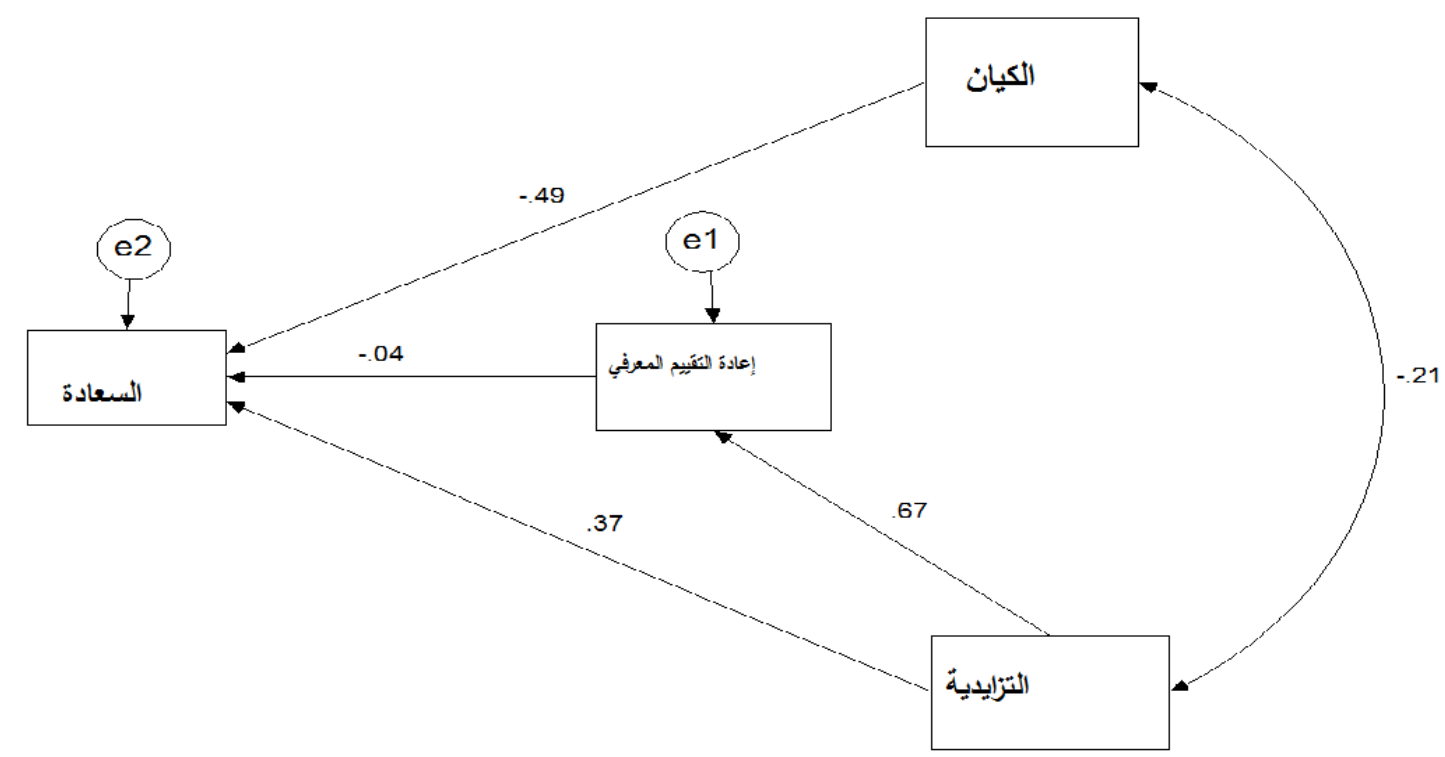

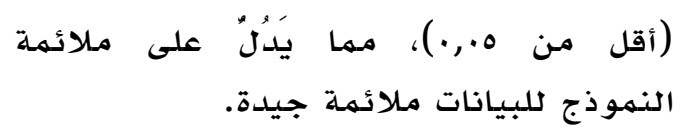

كَمَا تمَّ استخراج قيمة اختبـار مربع كاي (1,V1) (Chi-square)

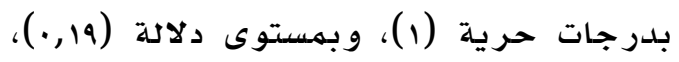

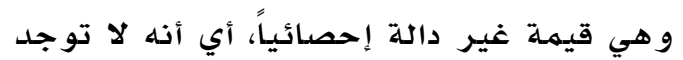

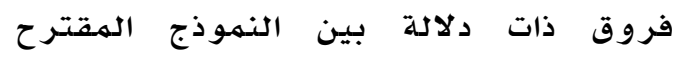

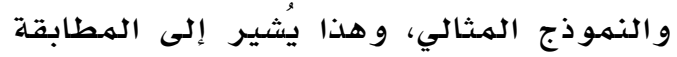

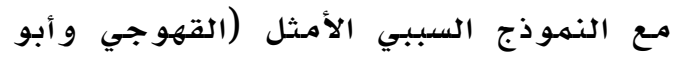

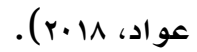

وبعد التحقق من مطابقة النموذج المقترح

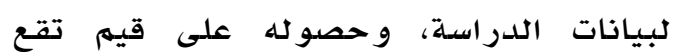

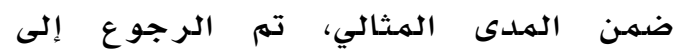

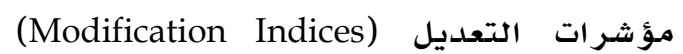
التي يقدمها بر نامـج (AMOS) في سبيل تحسين النهوذج الهقتر ح أظهر البر نامـج عدم

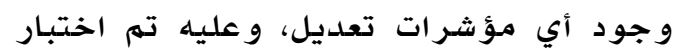

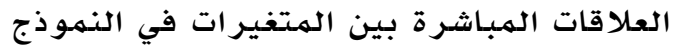

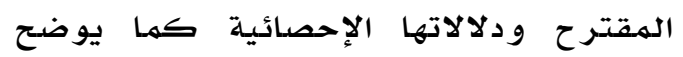

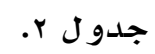

$$
\text { جدول }
$$

مؤشرات المطابقة للنموذج الافتراضي المقترح حدود الثقة

\begin{tabular}{|c|c|c|}
\hline 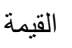 & 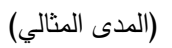 & 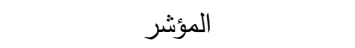 \\
\hline$\cdot, 99$ & $1-\cdot, 9$. & GFI (مؤشر جودة المطابقة) \\
\hline$\cdot, 91$ & $1-\cdot, 9$. & NFI (مؤشر المطابقة المعياري) \\
\hline$\cdot, 99$ & $1-\cdot, 9$ & CFI \\
\hline$\cdot, 90$ & $1-\cdot, 9$. & TLI (مؤشر تاكر_لويس) TLI \\
\hline$\cdot, 9$ & $1-\cdot, 9$. & AGFI (مؤشر جودة المطابقة \\
\hline
\end{tabular}

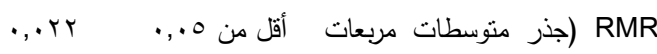
البواقي)

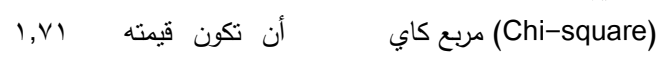

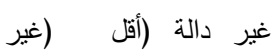

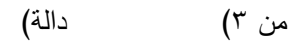

يتّضح من جدول 1 مطابقة النهموذج المقترح

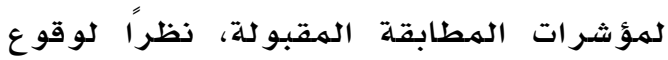

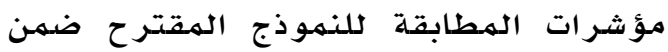
حلدود الثقة لمؤشرات الهـابقة المستخدمة في اختبار النموذذج، ومن ذلك حصول مؤشر

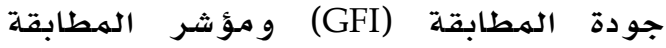
المعياري (NFI) و مؤشر المطابقة المقدارن و مؤشر مؤشر تاكر_لويس (CFI) على قيم مرتفعة عند حدود الثقة الهقبولة

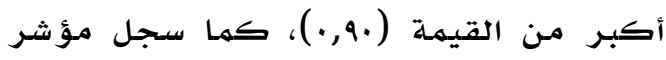

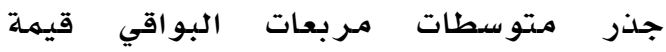

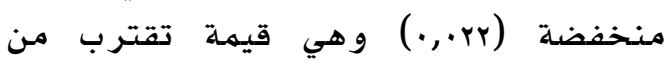
الصفر، ووهي بالتالي تقع ضهمن حدود الثقة 


\begin{tabular}{|c|c|c|c|c|c|}
\hline \multicolumn{6}{|c|}{ جدول r r } \\
\hline الدلالة الإحصائية & القيم & الخطأ & معاملات الانحدار & معاملات & \\
\hline $\mathrm{p}$ & الحرجة & المعياري & غير المعيارية & الانحدار & المسار السببي \\
\hline & C.R & S.E & & المعيارية & \\
\hline$\cdot, \ldots *$ & ᄉ,Orl & $\cdot, \cdot \Delta r$ & $\cdot, \vee \cdots$ & $\cdot, T V T$ & التزايدية-> التقييم المعرفي \\
\hline$\cdot, \ldots *$ & $0,9 r \varepsilon-$ & זד. •, & • & $\cdot, \leqslant 9 \cdot-$ & الكيان-->> السعادة \\
\hline$\cdot, \ldots *$ & . דוז, & $\cdot, \cdot V Y$ & $\cdot, r \leq r$ & , rvo & التزايدية --> السعادة \\
\hline.$v r$ & - & $\cdot, \cdot 71$ & $\cdot, \cdot Y r-$ & -, & التقييم المعرفي -> السعادة \\
\hline
\end{tabular}
* مال عند مستوى الدلالة (

التأثير الهباشر بين النظرية التزايدية

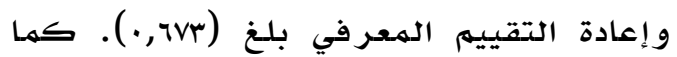

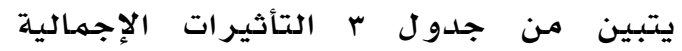

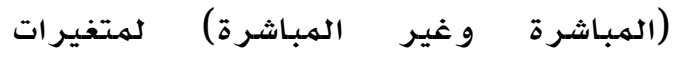
الدراسـة الخارجية والهبلة والداخلية على السعادة،

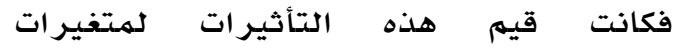
التزايدية، وإعادة التقييم المعر في ونظمرية

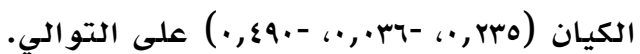
كما تم اختبار العلاقات غير المباشرة بين

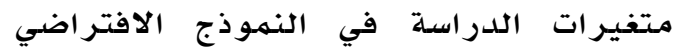
و يوضتح ذلك جدو ل ع.

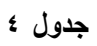

العلاقات غير المباشرة في النموذج المقترح

نظرية الكيان

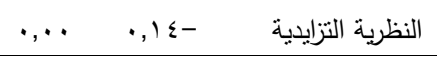

يتضح من جدول \& أن المسار غير المباشر

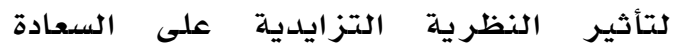

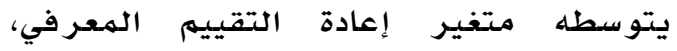

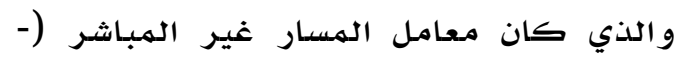

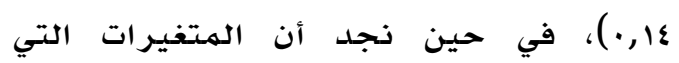

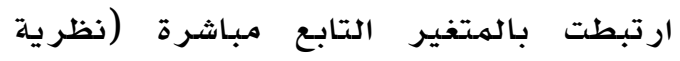

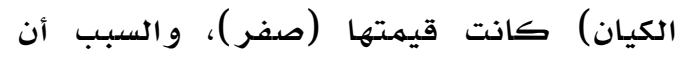
المتغير التابع غير الهمباشر تكون قيمته

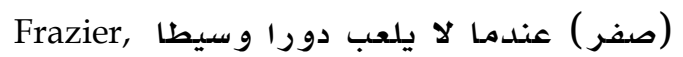

.(Tix \& Barron, 2004)

ولتحديد إن كان التأثير غير المباشر للنظرية التزايدية في السعادة عبر المتتغير

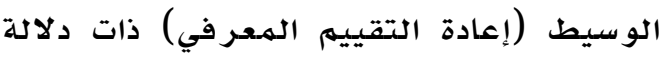

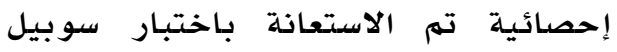

يظهر من خلال قيهم الدلالة الإحصائية

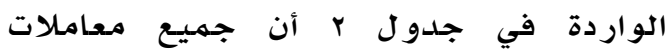
الانحدار دالة إحصائيًا عند مستوى الودى الدلادلة

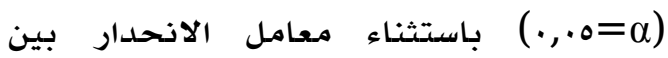
المتغير ين (إعادة التقييم الهعر في و السعادة)،

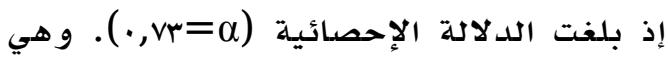

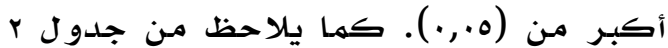
تباين التأثيرات المباشرة في السعادة؛ إذ أن معامل مسار النظرية التزايدية في التأثير المباشر على السعادة موجبا بهعامل تأثير المرير

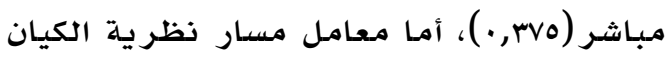

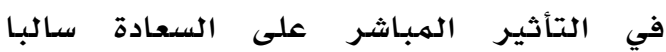
بهعامل تأثير مباشر (--9وء, •).

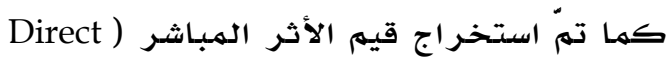
(Effects و الأثر الإجمالي (Total Effects) بين متغيرات الدراسة حسب النهوذذ الافتر اضي

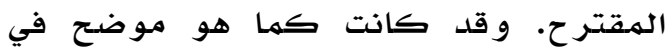
جدول

$$
\text { جدول r الأمبر }
$$

حجم الأثر المباشر والأثر الإجمالي لمتغيرات النموذج الافتراضي (بالقيم المعيارية)

\begin{tabular}{|c|c|c|}
\hline الأثر الإجمالي & الأثر المباشر & المتغير \\
\hline$\cdot, T \vee T$ & • & التزايدية -> التقييم \\
\hline$-\cdot, \leqslant 9$. & $-\cdot, \leqslant 9$. & الكيان --> السعادة \\
\hline סדז, & • rvo & التزايدية -->> السعادة \\
\hline 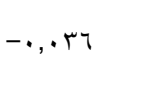 & דיזי,. & 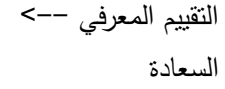 \\
\hline
\end{tabular}

يتضسح من جدول r م وجود مسارات مباشرة

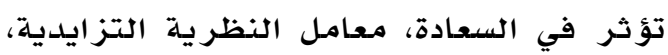
و إعادة التقييم المعرفي ونظرية الكيان

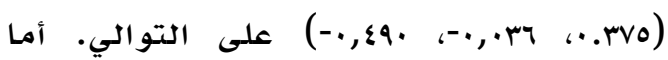


تفسير هذه النتيجة في ضوء الاعتقاد إلى أن

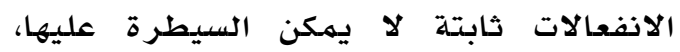

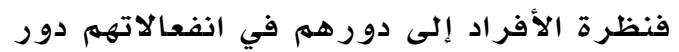

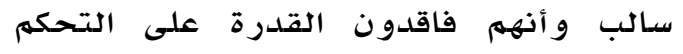

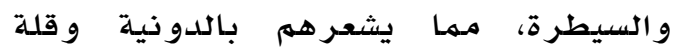
الحيلة و الضعف في مواجهة الأحداث المسببية

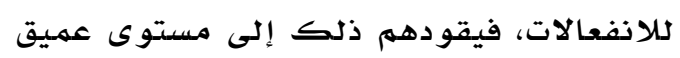

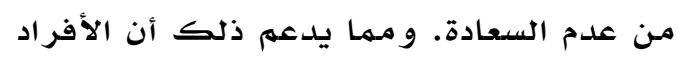
ذوي نظرية الكيان يوظفون العزو الداخلي المستقر مـع الفشل في توظيف استر اتيجيات

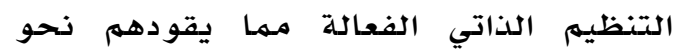

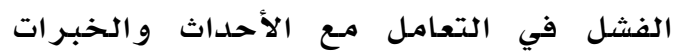
الهـحيطة (King \& Rosa, 2019). ويمكن تفسير حصول العلاقة المباشرة بين

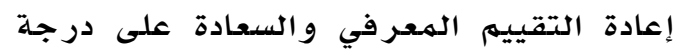

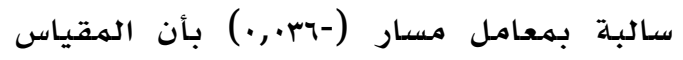
يتضمن درجة مـن عدم النضوج في قياس

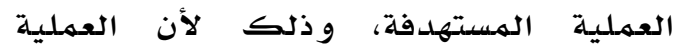
تتضمن درجة من الغموض وضل وعدم توصل الباحثين إلى مقاييس يمكن الركونه دون إليها

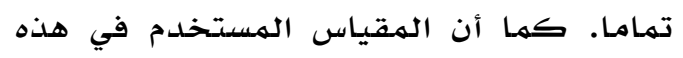

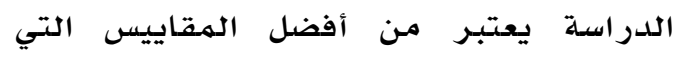
توصل إليها الباحثون، إلا أن معظم فقر اته

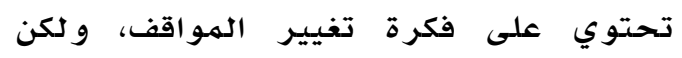
التغيير في طريقة التفكير دون توجيه محدد

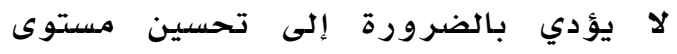

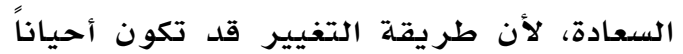
باتجاه خاطىء.

أما العلاقة غير المباشرة بين النظرية

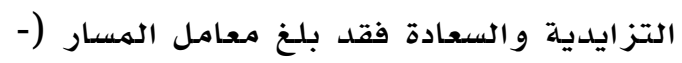

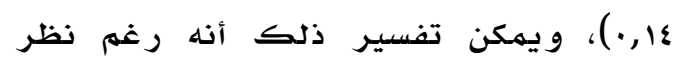

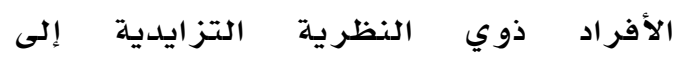

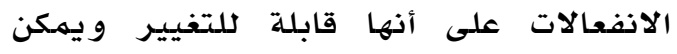

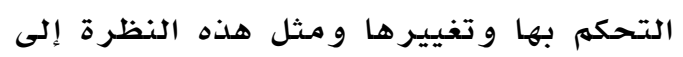

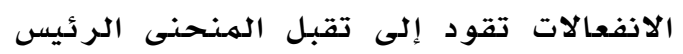

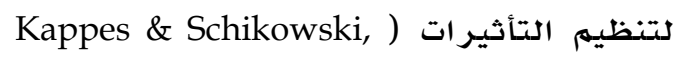

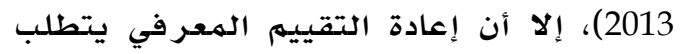

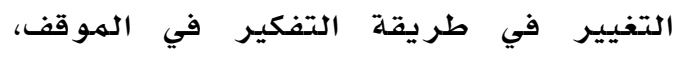
والذي قد يعد هروبا لحظيا في المـوقف مـما

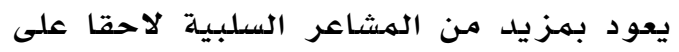

(SOBEL TEST)

$$
\text { و الذي أعطى القيمة (0؟), ). }
$$

\section{مناقشة النتائج}

يمكن تفسير النتيجة وفق النموذج المعرفي

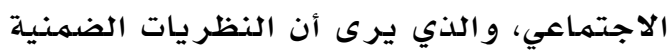

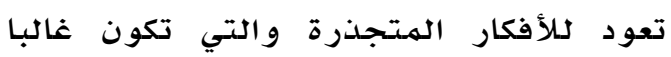
غير واعية بطبيعة الانفعال، والتي تعمل كإطار معرفي يؤثر على السلو كل ويفسره

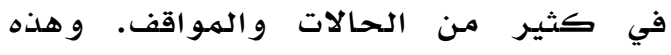
المعتقدات تنشئ نظاماً له معنى في في زئ زيادة حالات الرضا أو عدم الرضا ضـات في مختلف

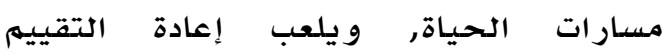

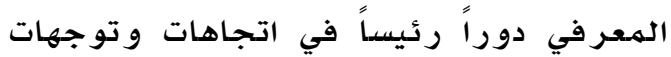

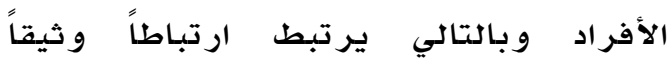
بالمعتقدات وحدوث حالة الدئ السعادة. إذ أظهرت النتائج قبول النهوذج المقترح

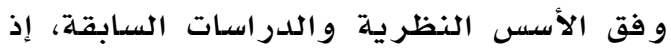

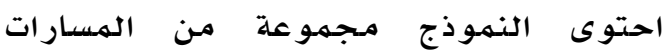

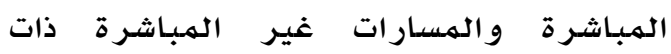

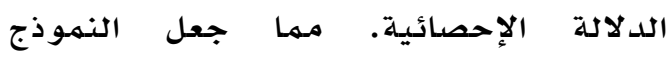

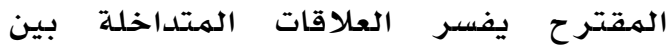

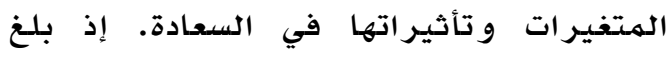
معامل مسار التأثير المباشر بين النير النظرية

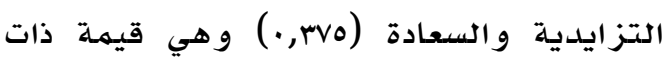

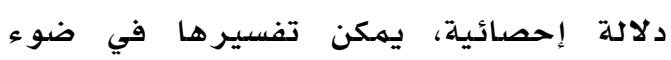

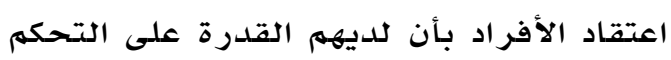

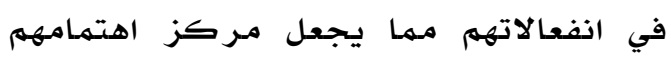

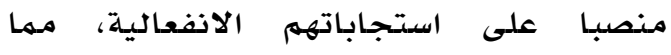
يزودهم بالرؤية التي تساعدهم في الفهم

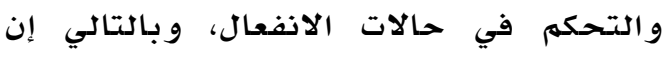
الأحداث التي قد تحمل مشاعر سلبية لالاتل

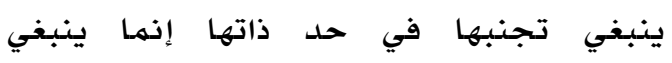

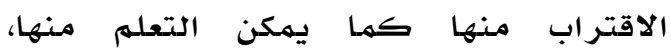

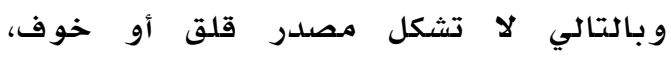
و بالتالي الحفاظ على حالة السعادة ( Kappes

.(\& Schikowski, 2013; King \& Rosa, 2019 أما التأثير المباشر بين نظرية الكيان

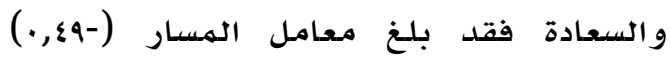
و هي قيمة سالبة ذات دلادلة إحصائية، و يمكن 


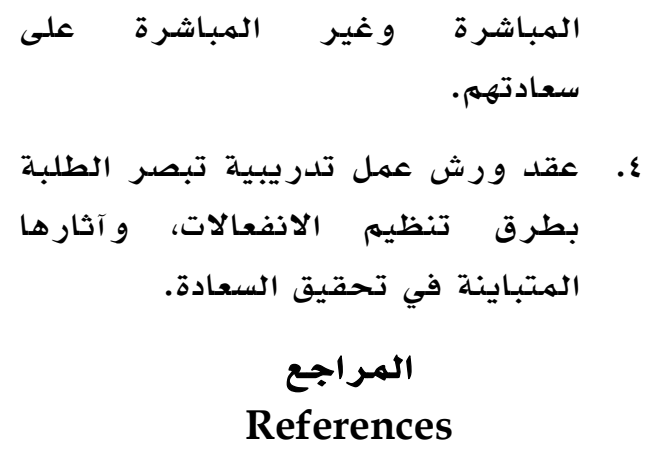

Argyle, M., Martin, M., \& Lu, L. (1995). Testing for Stress and Happiness: The Role of Social and Cognitive Factors. In C. D. Spielberger, \& I. G. Sarason (Eds.), Stress and Emotion (pp. 173187). Washington DC: Taylor \& Francis.

Asadi, S., Asadi, P., Tohidifar, A., Isazadeh, S. Matinpour, A. Maghami, M., Parhizgar, T. \& Hashemzadeh,A.(2014).Examining relationship of difficulties in emotion regulation (DiER) with mental health in the first male high school students in Tabriz. European Journal of Experimental Biology.4(2),188-197.

Berking, M., \& Whitley, R. (2014). Affect regulation training: A practitioner's manual. New York: Springer.

Bradburn, N. (1969). The structure of psychological well-being. Chicago: Aldine.

Castella, K. (2017). Implicit Theories And Emotion Regulation: Beliefs About Emotions And Their Role In Psychological Health And Well-Being.Unpublished

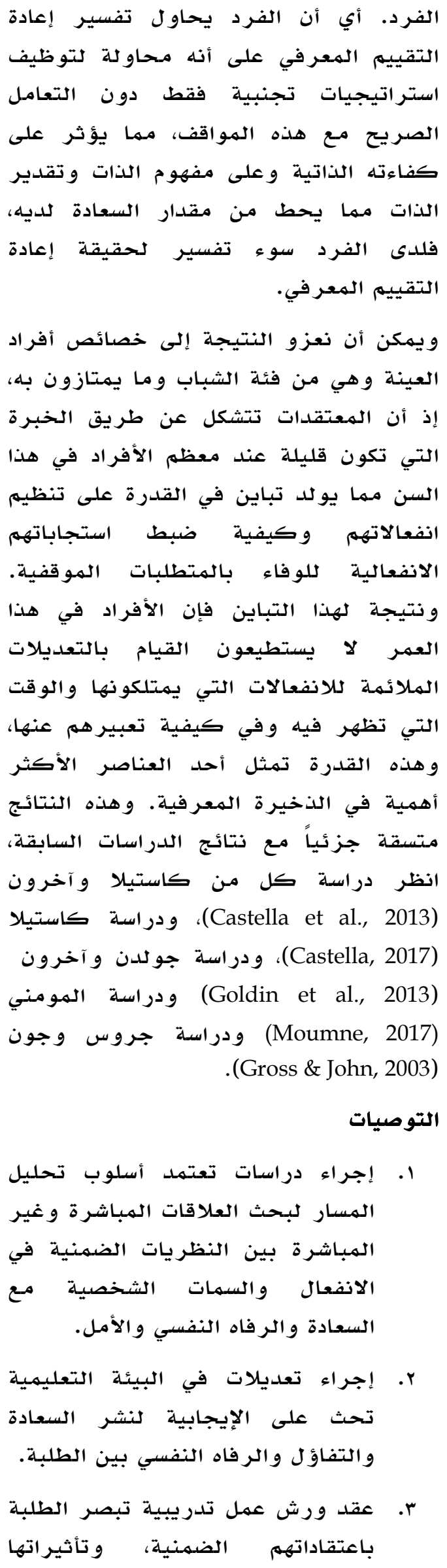


Doctoral Dissertation, Australian National University.

De Castella, K., Goldin, P. R., Jazaieri, H., Ziv, M., Dweck, C. S., \& Gross, J. J. (2013). Beliefs About Emotion: Links to Emotion Regulation, Well-Being, and Psychological Distress. Basic and Applied Social Psychology, 35(6), 497-505

Castella, K., Platow M., Tamir M \& Gross J. (2018). Beliefs about emotion: implications for avoidance-based emotion regulation and psychological health. Cognition and Emotion.32(4), 773-795.

Chin, T. \& Rickard, N. (2013). Emotion regulation strategy mediates both positive and negative relationships between music uses and well-being. Psychology of Music.1-22.

Côté, S., Gyurak, A., \& Levenson, R. W. (2010). The ability to regulate emotion

is associated with greater well-being, income, and socioeconomic status.

Emotion, 10(6), 923-933.

Csikszentmihalyi, M., \& Hunter, J. (2003). Happiness in Everyday Life: the Uses of Experience Sampling. Journal of Happiness Studies, 4, 185-199.

Diener, Ed., \& Eunkook M. Suh. (2000). Cultue and Subjective Well-Being. Cambridge, Massachusetts: MIT press.

Doğan, T., \& Akıncı Çötok, N. (2011). Adaptation of the short form of the Oxford Happiness Questionnaire into Turkish: A validity and reliability study. Turkish Psychological Counseling and Guidance Journal, 4(36), 165-172.

Flynn, E. (2016). Emotional and Behavioral Problems in Development: The Role of Implicit Theories of Emotion. Unpublished Doctoral Dissertation, University Of California.

Forgas, J., Baumeister, R., \& Tice, D. (2009). Psychology of self-regulation: Cognitive,affective, and motivational processes(Sydney Symposium of Social Psychology). New York: Psychology Press.

Frazier, P. A., Tix, A. P., \& Barron, K. E. (2004). Testing moderator and mediator effects in counseling psychology research. Journal of Counseling Psychology, 51(1), 115-134.

Goldin, P., Manber-Ball, T., Werner, K., Heimberg, R., Gross, J.(2009). Neural mechanisms of cognitive reappraisal of negative self-beliefs in social anxiety disorder. Biol Psychiatry, 66, 1091-1099.

Gross, J .J \& John, O. P. (2003). Individual Differences in Two Emotion Regulation Processes: Implications for Affect, Relationships, and Well-Being. Journal of Personality and Social Psychology, 85, 348-362.

Gross, J. J., \& Thompson, R. A. (2007). Emotion Regulation: Conceptual Foundations. In J. J. Gross (Ed.), Handbook of Emotion Regulation (pp. 3-24). New York: Guilford Press.

Kappes. A. \& Schikowski, A. (2013). Implicit theories of emotion shape regulation of negative affect. Cognition Emotion. Retrieved 3 January, 2019, from:

https://www.researchgate.net/public ation/234041875 Implicit theories of emotion shape regulation of negative affectge and Culture.

Khan, R. (2009). The Perception of Happiness: Role of Age and Culture. Unpublished Doctoral Dissertation, Kean University.

Khine, M. (2013). Application of Structural Equation Modeling in Educational Research and Practice. Rotterdam, The Netherland: Sense Publishers.

King, R. B., \& dela Rosa, E. D. (2019). Are your emotions under your control or not? Implicit theories of emotion predict well-being via cognitive reappraisal. Personality and Individual Differences, 138, 177-182.

Langevin, E.(2013). Undergraduate Student Happiness and Academic Performance: A Correlation Study. Unpublished Doctoral Dissertation, University Of Phoenix.

Lebowitz,M.S.,\&Dovidio, J.F. (2015). Implications ofemotion regulation strategies for empathic concern, social 
attitudes, and helping behavior. Emotion (Washington, D.C.), 15(2), 187-194.

Livingstone, K.(2012). The Effects of Implicit Theories of Emotion on Emotion Regulation and Experience. Unpublished Doctoral Dissertation, University of Oregon.

Lu, L .(2001).Understanding Happiness: A Look into the Chinese Folk Psychology. Journal of Happiness Studies,2(4) 407-432.

Moore, S. A., Zoellner, L. A., \& Mollenholt, N. (2008). Are expressive suppression and cognitive reappraisal associated with stress-related symptoms?. BehaviourResearch and Therapy, 46(9), 993-1000.

Moumne, S. (2017). An Implicit Theory Perspective on Emotion Regulation. Unpublished Doctoral Dissertation, McGill University.

Nistor, A .(2011). Developments on the Happiness Issues: a Review of the Research on Subjective Well being and Flow. Scientific Journal Studies, 3 (4), 58 $-66$.

Oliver, M. \& Raney, A. (2011). Entertainment as Pleasurable and Meaningful: Identifying Hedonic and Eudaimonic Motivations for Entertainment Consumption. Journal of Communication, 61(5), 984-1004.

Padhy, M., Chelli, K., \& Padiri, R. (2015). Optimism and Psychological WellBeing of Police Officers With Different Work Experiences. SAGE Open Journals,5(2) 1-7.

Phillips, J., De Freitas, J., Mott, C., Gruber, J., \& Knobe, J. (2017). True happiness: The role of morality in the folk concept of happiness. Journal of Experimental Psychology: General, 146(2), 165-181.

Richard, L .(2006). Happiness; Lessons from A New Science. NY: Penguin Layard.

Ryan, R., \&Deci, E .(2001). On Happiness and Human Potentials: A review of Research on Hedonic and Eudaemonic Well-Being. Annual Review of Psychology, 52, 141-166. World Health
Organization .(1997). Program on Mental Health. WHOQOL: Measuring Quality of Life. Division of Mental Health and Prevention of Substance Abuse .World Health Organization.

Retrieved5.12.2018 from: http://www.who.int/mental_health/ media/68.pdf.

Ryff, C. D. (1989). Happiness is everything, or is it? Explorations on the meaning of psychological wellbeing. Journal of Personality and Social Psychology, 57(6), 1069-1081.

Seligman, M.(2004). Can Happiness be Taught. The Mit pressJournals, 133(2), 80-87.

Shin, D. and Johnson, D. (1978) Avowed Happiness as an Overall Assessment of the Quality of Life. Social Indicators Research, 5, 475-492.

Tamir, M. (2016). Why Do People Regulate Their Emotions? A Taxonomy of Motives in Emotion Regulation.Personality and Social Psychology Review, 20(3), 199-222.

Tamir, M., John, O., Srivastava, S. \& Gross, J. (2007). Implicit Theories of Emotion: Affective and Social Outcomes Across a Major Life Transition. Journal of Personality and Social Psychology. 92 (4), 731-744.

Verzeletti, C., Zammuner, V. L., Galli, C., \& Agnoli, S. (2016). Emotion regulation strategies and psychosocial well-being in adolescence. Cogent Psychology, 3(1).

Werner, K. H., \& Gross, J. J. (2009). Emotion regulation and psychopathology: A conceptual framework. In A. Kring\& D. Sloan (Eds.), Emotion regulation and psychopathology: A transdiagnostic approach to etiology and treatment (pp.13). New York: Guilford Press. 